\title{
Bioactive Pigments from Marine Bacteria: Applications and Physiological Roles
}

\author{
Azamjon B. Soliev, Kakushi Hosokawa, and Keiichi Enomoto \\ Department of Environmental Systems Engineering, Kochi University of Technology, 185 Miyanokuchi, Tosayamada, Kami, \\ Kochi 782-8502, Japan \\ Correspondence should be addressed to Keiichi Enomoto, enomoto.keiichi@kochi-tech.ac.jp
}

Received 15 January 2011; Accepted 28 June 2011

Copyright (C) 2011 Azamjon B. Soliev et al. This is an open access article distributed under the Creative Commons Attribution License, which permits unrestricted use, distribution, and reproduction in any medium, provided the original work is properly cited.

\begin{abstract}
Research into natural products from the marine environment, including microorganisms, has rapidly increased over the past two decades. Despite the enormous difficulty in isolating and harvesting marine bacteria, microbial metabolites are increasingly attractive to science because of their broad-ranging pharmacological activities, especially those with unique color pigments. This current review paper gives an overview of the pigmented natural compounds isolated from bacteria of marine origin, based on accumulated data in the literature. We review the biological activities of marine compounds, including recent advances in the study of pharmacological effects and other commercial applications, in addition to the biosynthesis and physiological roles of associated pigments. Chemical structures of the bioactive compounds discussed are also presented.
\end{abstract}

\section{Introduction}

1.1. Marine Bacteria and Its Role in Life Sciences. A wide variety of diseases and medical problems represent a challenging threat to humans, who since ancient times have searched for natural compounds from plants, animals, and other sources to treat them. Although the process of finding effective treatments against fatal diseases is difficult, extensive searches for natural bioactive compounds have previously yielded some successful results. The isolation and identification of specific natural compounds led to the development of folk medicine, and humans learned to separate the isolates into medicinal drugs, which could be used to treat different diseases, and poisonous substances, which could be used for nonmedicinal purposes (i.e., during tribal wars, hunting, etc.). Statistically, at least $50 \%$ of the existing drugs that are used to treat human illnesses are derived from natural products, most of which are obtained from terrestrial organisms [1]. However, due to continuous and exhaustive research, land-based natural bioactive compounds have become increasingly difficult to find. Instead, water-based natural compounds have become a more promising source, not only from a pharmacological view, but also for industrial and commercial applications.

Theoretically, life is considered to have originated in the sea and, as a result of evolutionary changes, developed into a wide variety of diverse biological systems. The Earth's surface consists of $70 \%$ water, which is inhabited by $80 \%$ of all life forms [1], and consequently aquatic organisms have a greater diversity than their terrestrial counterparts. As research into the marine environment is still in its early phases, many mysteries associated with aquatic fauna and flora have yet to be discovered. Therefore, the marine environment has recently become an attractive research subject for many investigations, because of its rich biodiversity. Despite being comprised of a diverse ecosystem, the search for marine metabolites is difficult because of the inaccessibility and nonculturability of the majority of organisms [2]. Nevertheless, the existing technologies like deep seawater pumping facilities, scuba diving, and other available equipments, have facilitated investigation of the sea environment. As a result, scientific research has increasingly focused on marine biochemistry, microbiology, and biotechnology.

Microorganisms and their isolates represent a major source of undiscovered scientific potential. It should be noted that the number of microbial organisms isolated from the vast ocean territories continues to increase each year. Consequently, natural products isolated from microorganisms inhabiting environments other than soil are an attractive research tool, not only for biochemists and microbiologists, 
but also for pharmacologists and clinicians. Laatsch [3] described the isolation and description of nearly 250 marine bacterial metabolites versus 150 isolated from terrestrial bacteria between 2000 and 2005. Research into marine microorganisms and their metabolites has therefore become a major task in the search for novel pharmaceuticals.

Although many compounds show promising biological activities, it is difficult to point out any particular bioactive agent that has readily been commercialized as a medicine. Currently, 13 natural products isolated from marine microorganisms are being tested in different phases of clinical trials, and a large number of others are in preclinical investigations [4], thus highlighting the potential of marine natural compounds.

Despite thousands of marine bioactive compounds having been isolated and identified, in this paper, we will focus on the pharmacologically active pigmented compounds produced by marine microorganisms exhibiting in vitro or in vivo biological activities. Although pigmented compounds produced by terrestrial bacteria are beyond the scope of this review, specific examples will still be mentioned for comparative purposes, to outline common biological activities or because identical pigments were isolated from both types of microorganisms.

\subsection{Marine Microorganisms and Their Bioactive Isolates.} Marine and terrestrial microfloras differ from each other due to the influence of their respective environmental conditions. Microorganisms living in the sea must be able to survive and grow in the water environment with low nutrition, high salinity, and high pressure. That is why most bacteria isolated from seawater are Gram-negative rods, as it is postulated that their outer membrane structure is evolutionarily adapted to aquatic environmental factors. Marine microorganisms can be divided on the basis of habitat into psychrophiles (living at low temperatures), halophiles (living at high salinity), and barophiles (living under high pressure). Although these characteristics highlight the differences between marine and terrestrial microorganisms, it remains difficult to separate bacterial genera on the basis of habitat due to the ubiquitous presence of similar species in both environments. As such, most bioactive compounds have been isolated from bacteria in both environments.

Marine bacteria, however, are attractive to researchers because they can potentially produce compounds with unique biological properties [5]. Until now, marine Streptomyces, Pseudomonas, Pseudoalteromonas, Bacillus, Vibrio, and Cytophaga isolated from seawater, sediments, algae, and marine invertebrates are known to produce bioactive agents. They are able to produce indole derivatives (quinones and violacein), alkaloids (prodiginines and tambjamines), polyenes, macrolides, peptides, and terpenoids. Examples of bioactive-pigmented compounds isolated from marine (and some terrestrial) bacteria are discussed below.

\section{Pigments from Marine Bacteria}

Bioactive pigments from marine bacteria are summarized in Table 1.
2.1. Prodiginines. Red-pigmented prodigiosin compounds were first isolated from the ubiquitous bacterium Serratia marcescens and identified as secondary metabolites. The common aromatic chemical structure of these pigmented compounds was first named prodiginine by Gerber [6] (Figure 1). Prodigiosin was the first prodiginine for which the chemical structure was determined [7]. The name "prodigiosin" has been attributed to the isolation of prodigiosin from Bacillus prodigiosus bacterium (later renamed Serratia marcescens) [8], which was historically famed for the mysterious "bleeding bread" report $[9,10]$. Prodiginines share a common pyrrolyldipyrromethene core structure and have a wide variety of biological properties, including antibacterial, antifungal, antimalarial, antibiotic, immunosuppressive, and anticancer activities $[9,11]$. Such properties potentially make them one of the most powerful research tools in the past decade.

There are many research reports and reviews regarding prodiginines and their biological activity investigations. In addition to the Serratia, several species of marine bacteria of the genera Streptomyces [8], Actinomadura [8], Pseudomonas [12], Pseudoalteromonas [13-18], and others [19] have also been reported to produce prodigiosin and related compounds. In particular, Alteromonas denitrificans, which was isolated from the fjord systems off the west coast of Norway [16] and later reclassified as Pseudoalteromonas denitrificans [20], has been reported to produce cycloprodigiosin. This compound has immunosuppressive, antimalarial, and apoptosis-inducing activities $[18,21,22]$. Pseudoalteromonas rubra, found in the Mediterranean coastal waters [13], also produces cycloprodigiosin, in addition to prodigiosins $[14,15] . \alpha$-Proteobacteria isolated from a marine tunicate collected in Zamboanga, Philippines, was reported to produce heptyl prodigiosin. In vitro antimalarial activity against Plasmodium falciparum 3D7 $\left(\mathrm{IC}_{50}=0.068 \mathrm{mM}\right.$ and SI $\left.=20\right)$ was about 20 times the in vitro cytotoxic activity against L5178Y mouse lymphocytes [23]. In vivo experiments using Plasmodium berghei-infected mice, at concentrations of $5 \mathrm{mg} / \mathrm{kg}$ and $20 \mathrm{mg} / \mathrm{kg}$, significantly increased their survival, while also causing sclerotic lesions at the site of injection.

Other bacteria reported to produce red pigments include Hahella [24], Vibrio [25], Zooshikella [26], and Pseudoalteromonas [17], isolated from the coasts of Korea, Taiwan, and Japan. Kim et al. [27] identified red-pigmented prodiginines from Hahella chejuensis. Nakashima et al. also evaluated the biological activity of similar prodiginines from a bacterium assumed to belong to the genus Hahella [28]. Red pigment-producing bacterial species have further been isolated from river water $[29,30]$ and even from a swimming pool [31]. The most active prodiginine derivatives have already entered clinical trials as potential drugs against different cancer types [9].

Japan is surrounded by sea and has a bordering coastline of the Pacific Ocean in the South and the Sea of Japan in the North and West, and is consequently rich in marine re-sources. Therefore, one of the main tasks of our research group is to investigate the marine environment and its biodiversity, especially marine microorganisms and their respective metabolites. 
TABLE 1: Biologically active pigmented compounds isolated from marine bacteria.

\begin{tabular}{|c|c|c|c|}
\hline Pigment & Activity & Bacterial strains & References \\
\hline (1) Undecylprodigiosin & Anticancer & Streptomyces rubber & {$[8]$} \\
\hline (2) Cycloprodigiosin & Immunosuppressant; Anticancer; Antimalarial & Pseudoalteromonas denitrificans & {$[18,21,22]$} \\
\hline (3) Heptyl prodigiosin & Antiplasmodial & $\alpha$-Proteobacteria & {$[23]$} \\
\hline (4) Prodigiosin & Antibacterial; Anticancer; Algicidal & $\begin{array}{l}\text { Pseudoalteromonas rubra } \\
\text { Hahella chejuensis }\end{array}$ & $\begin{array}{l}{[14]} \\
{[27]}\end{array}$ \\
\hline (5) Astaxanthin (carotene) & Antioxidation & Agrobacterium aurantiacum & {$[34]$} \\
\hline (6) Violacein & $\begin{array}{l}\text { Antibiotic; Antiprotozoan; } \\
\text { Anticancer }\end{array}$ & $\begin{array}{l}\text { Pseudoalteromonas luteoviolacea } \\
\text { Pseudoalteromonas tunicata } \\
\text { Pseudoalteromonas sp. 520P1 } \\
\text { Collimonas CT }\end{array}$ & $\begin{array}{c}{[48,52,53]} \\
{[43]} \\
{[50]} \\
{[51]}\end{array}$ \\
\hline $\begin{array}{l}\text { (7) Methyl saphenate (phenazine } \\
\text { derivative) }\end{array}$ & Antibiotic & Pseudonocardia sp. B6273 & {$[63]$} \\
\hline (8) Phenazine derivatives & Cytotoxic & Bacillus sp. & {$[64]$} \\
\hline (9) Pyocyanin and pyorubrin & Antibacterial & Pseudomonas aeruginosa & {$[58]$} \\
\hline (10) Phenazine-1-carboxylic acid & Antibiotic & Pseudomonas aeruginosa & [59] \\
\hline $\begin{array}{l}\text { (11) 5,10-dihydrophencomycin } \\
\text { methyl ester }\end{array}$ & Antibiotic & Streptomycete sp. & {$[65]$} \\
\hline $\begin{array}{l}\text { (12) Fridamycin D, Himalomycin } \\
\text { A, Himalomycin B }\end{array}$ & Antibacterial & Streptomycete sp. B6921 & {$[68]$} \\
\hline $\begin{array}{l}\text { (13) Chinikomycin A and } \\
\text { Chinikomycin B, Manumycin A }\end{array}$ & Anticancer & Streptomycete sp. M045 & {$[71]$} \\
\hline $\begin{array}{l}\text { (14) Tambjamines (BE-18591, } \\
\text { pyrrole and their synthetic analogs) }\end{array}$ & Antibiotic, Anticancer & Pseudoalteromonas tunicata & {$[76,80]$} \\
\hline (15) Melanins & Protection from UV irradiation & $\begin{array}{l}\text { Vibrio cholerae } \\
\text { Shewanella colwelliana } \\
\text { Alteromonas nigrifaciens } \\
\text { Cellulophaga tyrosinoxydans }\end{array}$ & $\begin{array}{c}{[83,84]} \\
{[83,86]} \\
{[85]} \\
{[88]}\end{array}$ \\
\hline (16) Scytonemin & $\begin{array}{l}\text { Protection from UV irradiation } \\
\text { Anti-inflammatory, Antiproliferative }\end{array}$ & Cyanobacteria & {$[93]$} \\
\hline (17) Tryptanthrin & Antibiotic & $\begin{array}{l}\text { Cytophaga/Flexibacteria AM13,1 } \\
\text { strain }\end{array}$ & {$[95]$} \\
\hline
\end{tabular}

Previously, a total of 85 strains of bacteria were isolated by our research group from the Pacific Ocean at a depth of $320 \mathrm{~m}$ off Cape Muroto in the Kochi Prefecture of Japan. Among them, 13 strains were found to produce a purple pigment and one a red pigment. The red pigmentproducing bacterium was later named strain 1020R [32]. Detailed investigations have revealed that this strain is closely related to the prodigiosin-producing bacterium Pseudoalteromonas rubra and is Gram-negative with rod-shaped morphology. Physicochemical investigations have revealed that the pigment produced by this strain contains at least seven structurally similar prodiginine compounds. Chemical structures for four of these were successfully determined, and each only differed by the length of the alkyl chain attached to the $\mathrm{C}-3$ position of the C-ring. These compounds were further identified as prodigiosin and its analogues 2methyl-3-butyl-prodiginine, 2-methyl-3-pentyl-prodiginine (prodigiosin), 2-methyl-3-hexyl-prodiginine, and 2-methyl3-heptyl-prodiginine. Compound cytotoxicity to U937 leukemia cells was strongly dependent on the length of these alkyl side chains, which decreased with an increase in chain length. 2-methyl-3-butyl-prodiginine was the most potent cytotoxic pigment among them. Molecular investigations into the cytotoxic mechanisms of these prodiginine derivatives demonstrated effects on caspase- 3 activation and DNA fragmentation, indicating the potential to induce apoptosis in leukemia cells.

2.2. Carotenes. Carotenes are polyunsaturated hydrocarbons that contain 40 carbon atoms per molecule and are exclusively synthesized by plants. They are orange photosynthetic pigments important for plant photosynthesis. Recently, an unusual halophilic bacterium, which requires $15-25 \%$ salt for its normal growth, was found in Santa Pola near Alicante and on the Balearic island of Mallorca, Spain. It appeared to be red or pink due to a wide variety of isoprenoid compounds (phytoene, phytofluene, lycopene, and $\beta$-carotene) produced by this prokaryote. Oren and Rodríguez-Valera [33] investigated red-pigmented saltern crystallizer ponds in these areas of Spain and demonstrated that the pigments were carotenoid or carotenoid-like compounds produced by halophilic bacteria related to the Cytophaga-FlavobacteriumBacteroides group. Thus, it has been shown that Salinibacter is an important component of the microbial community 


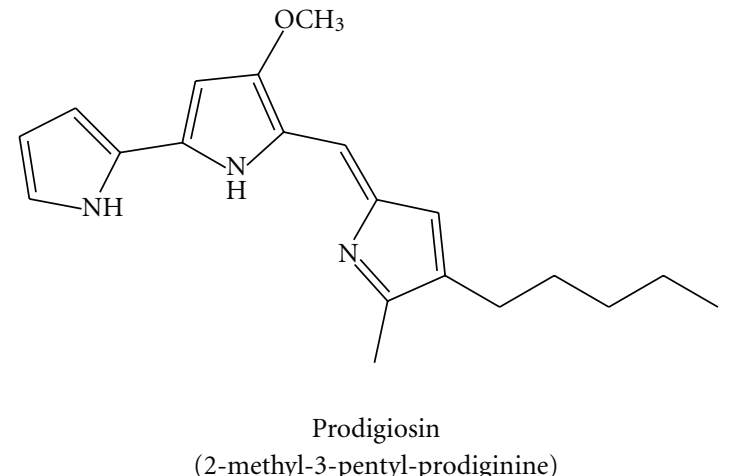

(2-methyl-3-pentyl-prodiginine)

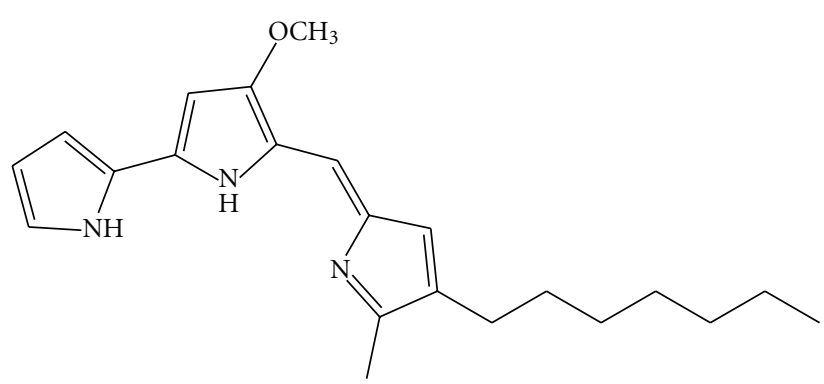

Heptyl prodigiosin

(2-methyl-3-heptyl-prodiginine)

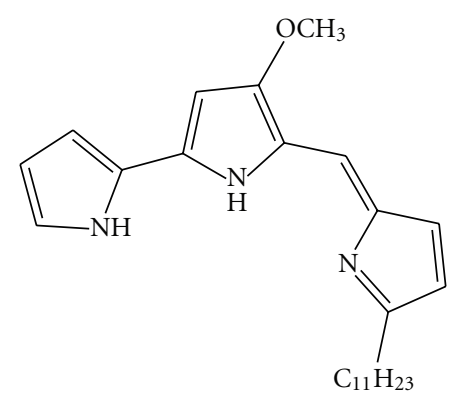

Undecylprodigiosin

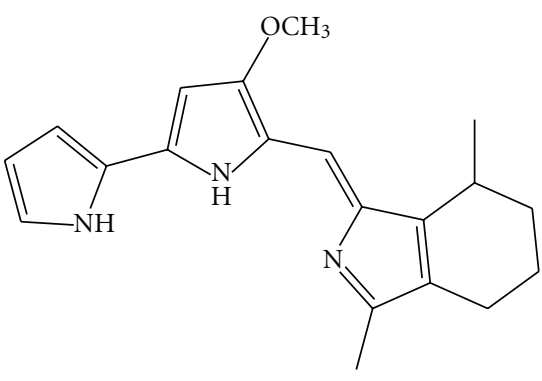

Cycloprodigiosin

Figure 1: Prodiginine derivatives.

that contributes to the red coloration of Spanish saltern ponds.

Astaxanthin is one of the carotenoids that have commercial value as a food supplement for humans and as food additives for animals and fish (Figure 2). A carotenoid biosynthesis gene cluster for the production of astaxanthin has been isolated from the marine bacterium Agrobacterium aurantiacum [34]. Recently, another astaxanthin-producing marine bacterium was isolated and identified as Paracoccus haeundaensis [35].

2.3. Violacein. The violet pigment violacein is an indole derivative, predominantly isolated from bacteria of the genus Chromobacterium that inhabit the soil and water of tropical and subtropical areas [36]. Over the past decade, the biosynthesis and biological activities of violacein have been extensively studied, and many scientific papers and reviews have been published [37-41]. Violacein has a variety of biological activities, including antiviral, antibacterial, antiulcerogenic, antileishmanial, and anticancer properties [36, 37, 41, 42] (Figure 3). Use of violacein as a chemical defense against eukaryotic predators has also been investigated [43-46].

One of the first published reports on violacein production by marine bacteria was by Hamilton and Austin [47]. This bacterial strain, Chromobacterium marinum, was isolated from open ocean waters and produced a blue pigment that was identified as violacein on the basis of physicochemical characteristics [47]. Later, Gauthier [48] described 16 violet-pigmented heterotrophic bacilli isolated from Mediterranean coastal waters and proposed the name Alteromonas luteo-violaceus for these strains. Another six bacterial species were also isolated by Gauthier et al. [49] from neritic waters on the French Mediterranean coast and were very similar to Alteromonas species. These species produced characteristic pigmentations ranging from pinkishbeige with reddish-brown diffusible pigment, lemon yellow, bright red turning carmine in old cultures, and orange to greenish-brown. Light violet, dark violet, or almost black pigments were also produced and later identified as violacein. The strains showed antibiotic activity against Staphylococcus aureus [49]. Subsequently, many other reports on violacein production have been published $[50,51]$.

Several purple pigment-producing Alteromonas species were also isolated from Kinko Bay in Kagoshima Prefecture, Japan. One of these, Alteromonas luteoviolacea (reclassified as Pseudoalteromonas luteoviolacea), is the only extensively characterized marine bacterium ever reported that produces violacein $[48,52,53]$. Previously, we have also reported 13 strains of Gram-negative, rod-shaped bacteria that produce a violacein-like purple pigment, which were isolated from the Pacific Ocean at a depth of $320 \mathrm{~m}$ off the coast of Cape Muroto, Kochi Prefecture, Japan [32]. Among them, two groups of novel violacein and deoxyviolacein producing marine bacteria were isolated and characterized in detail 
<smiles>CC1=C(/C=C/C(C)=C/C=C/C(C)=C/C=C/C=C(C)/C=C/C=C(C)/C=C/C2=C(C)C(=O)[C@@H](O)CC2(C)C)C(C)(C)C[C@H](O)C1=O</smiles>

Figure 2: Astaxanthin.

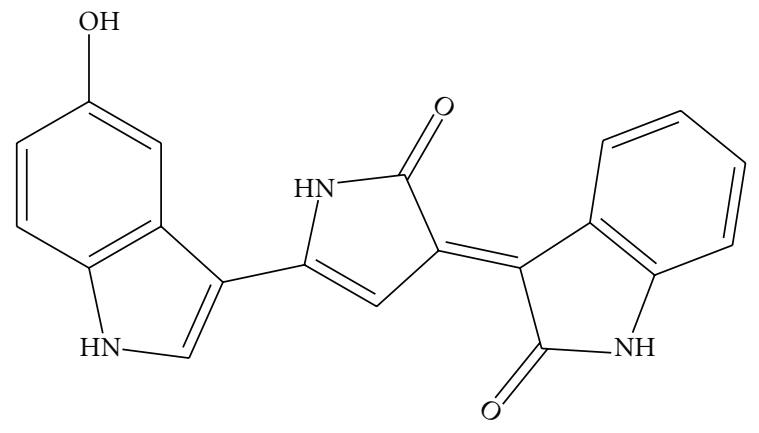

Violacein

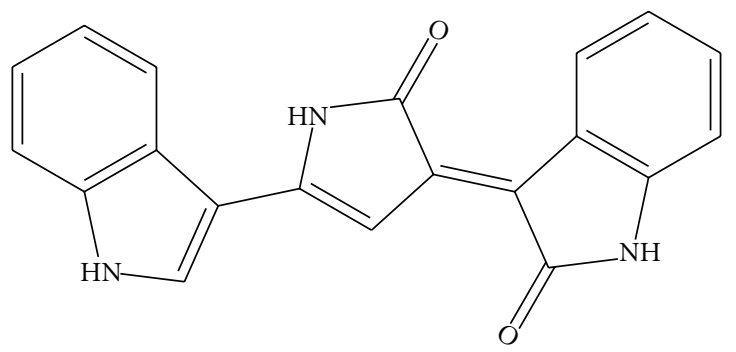

Deoxyviolacein

FIgURE 3: Violacein and deoxyviolacein.

[50]. Biological investigations of violacein produced by these strains revealed potent cytotoxic effects against U937 and HL60 leukemia cell lines, with an $\mathrm{IC}_{50}$ value of $0.5-1 \mu \mathrm{M}$. The molecular mechanisms currently known to be involved in violacein cytotoxicity include caspases activation, chromatin condensation, and DNA fragmentation, which all contribute to cell apoptosis. Recently, we also demonstrated that the protein kinases actively involved in the signal transduction pathway are also targeted by violacein.

2.4. Phenazine Compounds. Phenazines are redox-active, small nitrogen-containing aromatic compounds produced by a diverse range of bacterial genera, including Streptomyces (terrestrial), Pseudomonas (ubiquitous), Actinomycetes (terrestrial and aquatic), Pelagibacter (aquatic), and Vibrio (aquatic), under the control of quorum sensing [54, 55] (Figure 4). These compounds were subjected to extensive studies due to their broad spectrum of antibiotic activities against other bacteria, fungi, or plant/animal tissues [56-62]. Phenazine color intensity may vary among the derivatives and range from blue, green, purple, yellow, red to even brown $[58,63]$. More than 6,000 phenazine derivatives have been identified and described during the last two centuries [59].

Maskey et al. [63] reported the isolation of two yellow pigments from the marine Pseudonocardia sp. B6273, a member of the Actinomycetes. Structural investigations identified the two pigments as novel phenazostatin $\mathrm{D}$, inactive against the tested microorganisms, and methyl saphenate, a known phenazine antibiotic. Li et al. [64] also reported the isolation of a novel phenazine derivative with cytotoxic effects against P388 cells, together with six previously identified compounds from the marine Bacillus sp., collected from a $\mathrm{Pa}-$ cific deep-sea sediment sample at a depth of $5059 \mathrm{~m}$. A novel phenazine derivative with antibiotic activity, identified as 5,10-dihydrophencomycin methyl ester, along with (2hydroxyphenyl)-acetamide, menaquinone MK9 (II, III, VIII, IX-H8), and phencomycin, was isolated from an unidentified marine Streptomyces sp. by Pusecker et al. [65].

Pyocyanin and 1-hydroxyphenazine also downregulate the ciliary beat frequency of respiratory epithelial cells by reducing CAMP and ATP, alter the calcium concentration by inhibition of plasma membrane $\mathrm{Ca}^{2+}$-ATPase, and induce death in human neutrophils $[60,61,66]$. Due to the abundance and biotechnological application of Pseudomonas aeruginosa phenazines, pyocyanin and pyorubrin have also been suggested as food colorant pigments [58].

2.5. Quinones. Quinones are additional colored compounds with an aromatic ring structure that have been isolated from marine environment [67, 68] (Figure 5). Quinone derivatives range in color from yellow to red, exhibit antiviral, antiinfective, antimicrobial, insecticidal, and anticancer activities, and have many commercial applications as natural and artificial dyes and pigments $[69,70]$. 
<smiles>COC(=O)c1cccc2nc3c(C(C)O)cccc3nc12</smiles>

Methyl saphenate<smiles>Cn1c2cccc(=O)c-2nc2ccccc21</smiles>

Pyocyanin<smiles>CC(=O)c1cccc2nc3c(C(=O)O)cccc3nc12</smiles>

Phencomycin<smiles>Oc1cccc2nc3ccccc3nc12</smiles>

1-hydroxyphenazine<smiles>COC(=O)c1cccc2c1Nc1cccc(C(C)=O)c1N2</smiles>

5,10-dihydrophencomycin methyl ester

FIgURE 4: Phenazine derivatives.

Streptomyces sp. B6921 strain produced glycosylated pigmented anthracycline antibiotics, including fridamycin $\mathrm{D}$ and two new compounds, named himalomycin $\mathrm{A}$ and $\mathrm{B}$, each of which displayed similar levels of strong antibacterial activity against Bacillus subtilis, Streptomyces viridochromogenes (Tü 57), S. aureus, and Escherichia coli. This strain also produced rabelomycin, $N$-benzylacetamide, and $N$ - $\left(2^{\prime}-\right.$ phenylethyl) acetamide [68]. Two novel pigmented antitumor antibiotics, chinikomycin A and B, together with manumycin A, were isolated from a marine Streptomyces sp. strain
M045 [71]. The two chlorine containing quinone derivatives were shown not to have antiviral, antimicrobial, and phytotoxic activities; however, they exhibited antitumor activity against different human cancer cell lines. Chinikomycin A selectively inhibited the proliferation of mammary cancer, melanoma, and renal cancer cell lines, while chinikomycin $\mathrm{B}$ showed selective antitumor activity against a mammary cancer cell line [71].

Other bacteria, including a marine isolate Pseudomonas nigrifaciens (later reclassified as Alteromonas nigrifaciens), 


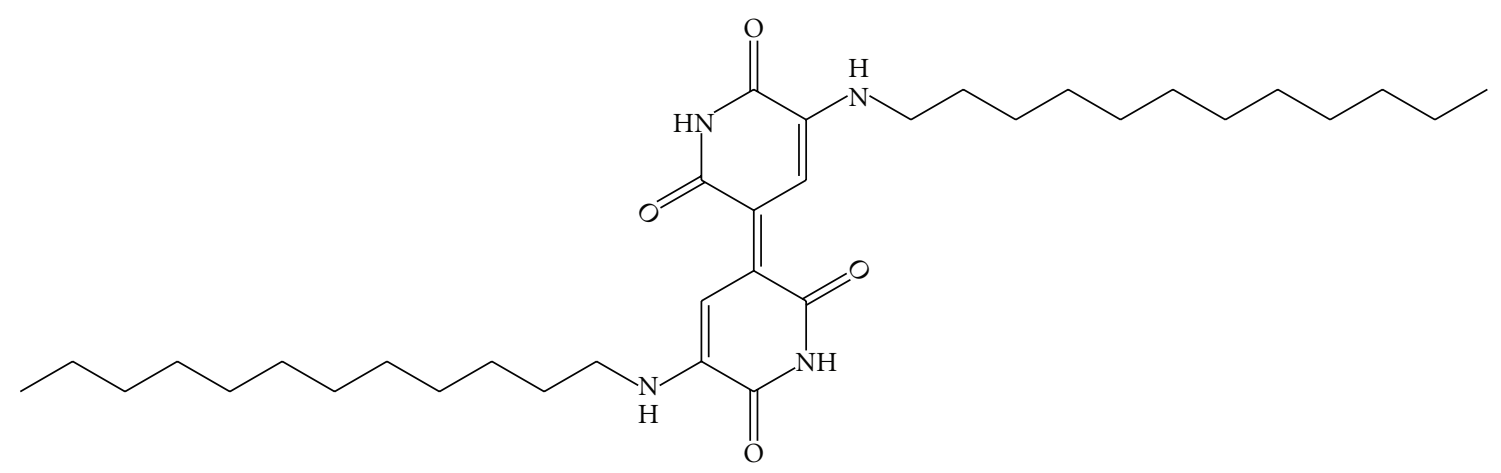

5,5' -didodecylamino- $4,4^{\prime}$-dihydroxy- $3,3^{\prime}$-diazodiphenoquinone- $\left(2,2^{\prime}\right)$<smiles></smiles><smiles>CC1CCC(OC2CCC(O)C(C)O2)C(C)O1</smiles>

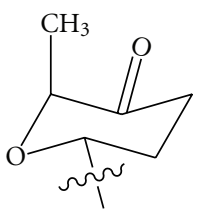

a

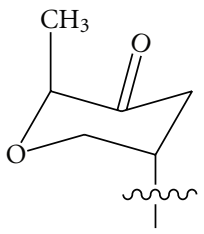

b

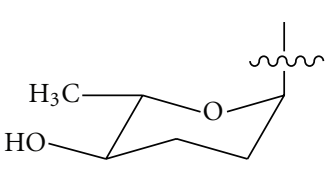

c

Fridamycin D: R1 = H, R2 = a, R3 = b;

Hymalomycin A: R1 = d, R2 = a, R3 = b;

Hymalomycin B: R1 = d, R2 = c, R3 = H<smiles>CCCC[C@H](C)/C=C(C)/C=C(\C)C(=O)Nc1cc(O)c(/C=C/C=C/C=C/C(=O)NC2=C(O)CCC2=O)c(Cl)c1O</smiles>

Chinikomycin A

Figure 5: Quinones. 


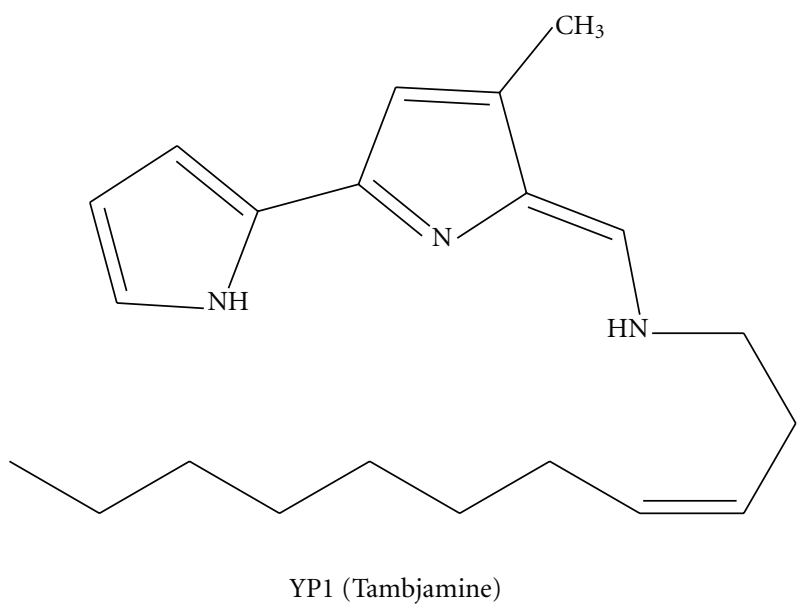

FIgURE 6: Tambjamine.

produce the blue pigment indigoidine [72]. Kobayashi et al. [73] isolated a new violet pigment with an alkylated indigoidine structure from Shewanella violacea, a deep-sea bacterium from sediments of Ryukyu Trench at a depth of $5110 \mathrm{~m}$. This pigment was established as $5,5^{\prime}$-didodecylamino- $4,4^{\prime}$-dihydroxy-3,3'-diazodiphenoquinone- $\left(2,2^{\prime}\right)$ based on $\mathrm{X}$-ray diffraction analysis of single crystals. It does not have antibiotic activity against E. coli; however, it could potentially be used as a dye because of its high stability and low solubility. Thus, it could be suitable for industrial applications.

2.6. Tambjamines. It has long been noticed that marine bacteria have the ability to prevent biofouling. Holmström et al. [74] found that, amongst the marine Pseudoalteromonas species, $P$. tunicata has the widest range of antibiofouling activities against microorganisms, including bacteria, invertebrate larvae, algal spores, protozoan, and fungi, and provides protection for host marine organisms. These activities were linked to the production of unidentified yellow and purple pigments [75]. Recently, this yellow pigment was isolated from $P$. tunicata and was identified as a new member of the tambjamine class of compounds [76].

Tambjamines (Figure 6) are alkaloids isolated from various marine organisms like bryozoans, nudibranchs, and ascidians [77-79]. This yellow pigment has also been isolated from marine bacteria [76]. The tambjamines also exhibit antibiotic activity against E. coli, Staphylococcus, Vibrio anguillarum [77], B. subtilis, and Candida albicans [80, 81] and displayed cytotoxic activity against several tumor cell lines [80]. Recently, Pinkerton et al. [80, 82] reported the first total synthesis of nine tambjamines and their antimicrobial and cytotoxic activities. All of the tested tambjamines showed antibacterial, antifungal, and cytotoxic effects that contributed to cell death through apoptosis, but not necrosis. These activities were, however, lesser than the positive control (doxorubicin) [80].

2.7. Melanins. Vibrio cholerae, Shewanella colwelliana, and Alteromonas nigrifaciens were some of the first marine bacterial strains described to produce melanin or melaninlike pigments [83-86]. The pigment synthesized by Vibrio cholerae was reported to be a type of allomelanin derived from homogentisic acid [87]. Melanin formation in $V$. cholerae is a consequence of alterations in tyrosine catabolism and not from the tyrosinase-catalyzed melanin synthetic pathway. Cellulophaga tyrosinoxydans was reported to have tyrosinase activity and produce a yellow pigment suggested to be a pheomelanin [88].

The most illustrative example of melanin-producing marine bacteria is the actinomycetes. This is particularly the case for the genus Streptomyces, from which most compounds with known biological activity have been isolated [89]. All Streptomyces strains are reported to use tyrosinases in the synthesis of melanin pigments [90]. Another important melanin-synthesizing bacterium is Marinomonas mediterranea, which produces black eumelanin from Ltyrosine [91].

2.8. Other Pigmented Compounds. Scytonemin, a yellowgreen pigment isolated from aquatic cyanobacteria, forms when the bacteria are exposed to sunlight (Figure 7). It protects bacteria by preventing about $85-90 \%$ of all UV-light from entering through the cell membrane [92]. High UVA irradiation inhibited photosynthesis and delayed cellular growth until sufficient amounts of scytonemin had been produced by the cyanobacteria. Scytonemin may also have anti-inflammatory and antiproliferative activities by inhibiting protein kinase $\mathrm{C} \beta(\mathrm{PKC} \beta)$, a well-known mediator of the inflammatory process, and polo-like protein kinase 1 (PLK1), a regulator of cell cycle progression [93]. In addition, scytonemin inhibited phorbol-induced mouse ear edema and the proliferation of human umbilical vein endothelial cells.

Recently, two $\gamma$-Proteobacteria strains of the genus Rheinheimera were isolated from the German Wadden Sea and from Øresund, Denmark that produced a deep blue pigment [94]. Structural analysis of the pigment revealed that this new compound has no similarity with any known blue pigments, like violacein and its derivatives. Due to its blue 


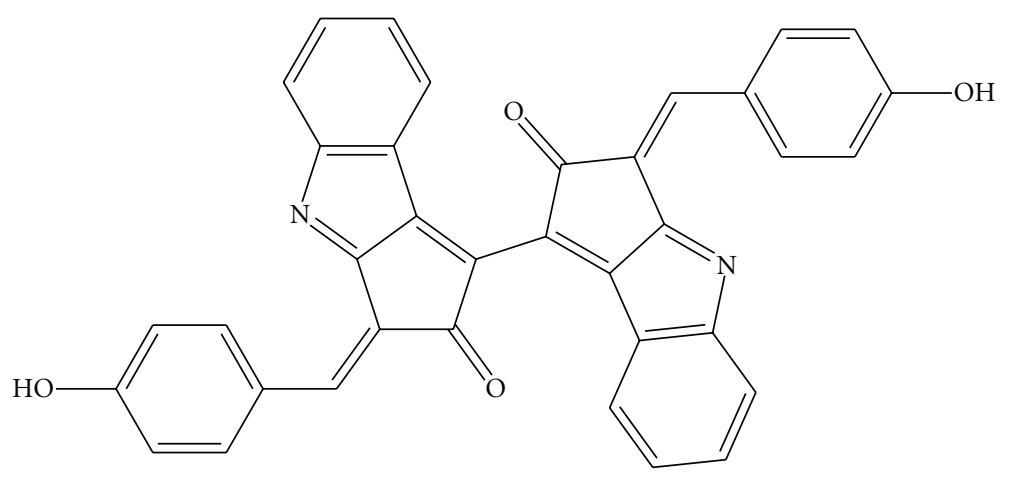

Scytonemin

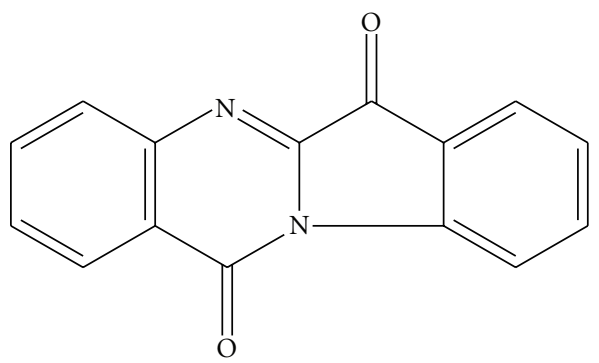

Tryptanthrin

Figure 7: Other pigmented compounds.

color and marine origin, the new pigment was named glaukothalin (from Greek glaukos "blue" and thalatta "sea"). The ecological role and biological activities of glaukothalin are currently under investigation.

AM13,1 strain, which was identified to belong to the Cytophaga/Flexibacteria cluster of North Sea bacteria, was found to produce yellow tryptanthrin, a rare compound that had never before been found in bacteria [95]. This compound was suggested to be a biocondensation product of anthranilic acid and isatin and exhibited a broad yet moderate antibiotic activity. Thus, the yellow color of the AM13,1 colonies was potentially due to their tryptanthrin content. In another yellow cultured Hel21 strain, pigment color may be a consequence of carotenoid zeaxanthin or one of the many vitamin $\mathrm{K}$ derivatives (e.g., menaquinone MK6) [95].

\section{Biosynthesis of Pigments}

Numerous reports detail the regulation and biosynthesis of bacterial secondary metabolites. Increased research and verification of specific bacterial pathways has predominantly been due to the antibiotic, immunosuppressive, and anticancer potential of these compounds. A brief discussion of this topic is given next, as detailed information is further provided in the cited references.

Biosynthesis of bacterial prodiginines has extensively been studied and reviewed $[96,97]$. Prodigiosin biosynthesis was proposed to originate during the enzymatic condensation of 2-methyl-3-n-amyl-pyrrole (MAP) and 4-methoxy2,2'-bipyrrole-5-carbaldehyde (MBC) precursors. Prodiginine biosynthetic gene clusters for Serratia sp. ATCC 39006 [98], Serratia marcescens ATCC 274 [98], Hahella chejuensis KCTC 2396 [27, 99], and Streptomyces coelicolor A3(2) [100] have been identified, sequenced, and expressed. Several gene clusters are involved in the biosynthetic pathway, depicted as pig in Serratia strains, red in S. coelicolor A3(2), and hap (numbered) in $H$. chejuensis KCTC 2396, with each encoding several proteins responsible for synthesis. The largest gene cluster found in S. coelicolor A3(2) consists of four transcriptional units, whereas the other three clusters 
are strongly homologous to each other and are arranged unidirectionally.

In Serratia strains, pigB-pigE genes were identified to encode proteins responsible for the biosynthesis of MAP and condensation with MBC to form prodigiosin [96, 97]. A common pathway of MBC biosynthesis is proposed for all strains, in which proline, acetate, serine, and S-adenosylmethionine are incorporated into the bipyrrole at the initial stage [97]. PigA, PigF, PigG, PigH, PigI, PigJ, PigM, and PigN in Serratia strains and RedE, RedI, RedM, RedN, RedO, RedW, RedV, and RedX proteins in S. coelicolor A3(2) have been determined to participate in MBC biosynthesis [97]. PigB, PigD, and PigE enzymes in Serratia strains were proposed to be involved in the MAP biosynthesis, which requires 2-octenal as the initial precursor [97]. Monopyrroles condense with $\mathrm{MBC}$ during the final step of prodigiosin and/or undecylprodigiosin biosynthesis. PigC and its homologues catalyze this condensation in bacteria.

Some prodiginines can also be produced when monopyrroles are supplied to colorless $S$. marcescens mutants [8]. Addition of monopyrroles directly to a culture medium or as a vapor across the culture surface of a colorless mutant of S. marcescens resulted in the strain becoming initially pink and later red, indicating prodiginine formation [8]. Similar prodiginine biosynthesis produced by exogenously adding MAP and MBC was observed in white strains of Serratia marcescens isolated from patients [101].

The violacein biosynthesis pathway and associated biosynthetic enzymes have been extensively studied [38, 40, 102], although certain reactions and intermediates are yet to be elucidated. Currently, this proposed system involves an operon of five genes, vioA-vioE, which are transcriptionally regulated by a quorum-sensing mechanism that uses acylhomoserine lactones as autoinducers. At the early stationary phase of bacterial growth, acylhomoserine lactones accumulate in the culture medium, inducing the transcription of the vio genes. Therefore, violacein is considered a typical secondary metabolite in bacteria. The first enzyme encoded by the vio gene operon, VioA, converts L-tryptophan to indole-3-pyruvic acid imine (IPA imine), and the second enzyme, VioB, catalyzes the reaction to convert IPA imine into an unidentified compound $\mathrm{X}$ (possibly an IPA imine dimer) $[103,104]$. Compound $X$ then undergoes successive reactions, catalyzed by the enzymes VioE, VioD, and VioC, to produce violacein.

Phenazine pigment biosynthesis reportedly involves shikimic acid as a precursor and forms chorismic acid as an intermediate product. Two molecules of chorismic acid then form phenazine-1,6-dicarboxylic acid, which is sequentially modified to create a variety of phenazine derivatives with different biological activities [105]. Pseudomonas aeruginosa PAO1 has two gene clusters (phzA1B1C1D1E1F1G1 and phzA2B2C2D2E2F2G2), with each cluster capable of producing phenazine-1-carboxylic acid (PCA) from chorismic acid [106]. It is proposed that PhzM and PhzS catalyze the subsequent conversion of PCA to pyocyanin. In addition, $\mathrm{PhzH}$ is responsible for producing phenazine-1-carboxamide from PCA.
Fridamycin, hymalomycin, and chinikomycin are typical bacterial compounds that share a quinone skeleton. However, little information regarding the biosynthesis of these compounds has been accumulated.

Detection and identification of the entire P. tunicata gene cluster involved in the biosynthetic pathway production of the tambjamine YP1 using recombinant E. coli was conducted by Australian researchers Burke et al. [107]. In total, 19 proteins encoded the Tam cluster participate in the postulated biosynthetic pathway. Among them, 12 were found to have high sequence similarity to the red proteins responsible for undecylprodigiosin synthesis in S. coelicolor A3(2) and the pig proteins involved in prodigiosin biosynthesis in Serratia sp. [107]. Such similarity in the chemical structures of these two classes of compounds results in tambjamines having two pyrrole rings while the prodiginines have three. As is the case for the prodiginines, 4-methoxy-2,2-bipyrrole5 -carbaldehyde (MBC) is initially formed from proline, serine, and malonyl CoA in the tambjamine biosynthetic pathway. A double bond is inserted by TamT and an amino group is transferred by TamH to dodecenoic acid activated by AfaA, which is predicted to be an acyl-CoA synthase. The resulting dodec-3-en-1-amine is condensed with MBC by TamQ to form tambjamine YP1 [107].

In addition to $V$. cholera, S. colwelliana, A. nigrifaciens, and $C$. tyrosinoxydans, melanin syntheses have also been reported in $M$. mediterranea, which contains the tyrosinase gene operon [108], and in an epiphytic Saccharophagus degradans 2-40 bacterium [109]. While the specific details of melanin formation continue to be debated, well-defined biosynthetic schemes have now been proposed. Two different biosynthetic pathways synthesize the eumelanins and pheomelanins. Both pathways are initiated by the oxidation of L-tyrosine to 3,4-dihydroxyphenylalanine (DOPA) and the subsequent creation of dopaquinone by tyrosinase. The latter product is transformed either to pheomelanin by combining with cystein and forming an intermediate S-cysteinyldopa and benzothiazine or to eumelanin with intermediate leucodopachrome, dopachrome (red), 5,6-dihydroxyindole, 5,6-indolequinone (yellow) formation [69].

Nostoc punctiforme ATCC 29133 is the only scytoneminproducing organism whose genome has been fully sequenced [110]. This scytonemin biosynthesis potentially involves a gene cluster consisting of 18 open reading frames (ORFs) (NpR1276 to NpR1259). Although, the functional roles of all these ORFs are not yet fully determined, some intriguing hypotheses have been proposed. In particular, both tyrosine and tryptophan are implicated as biosynthetic precursors for scytonemin in the pigment formation pathway. NpR1275, which functionally resembles leucine dehydrogenase, is utilized in the early stages of scytonemin synthesis in $N$. punctiforme, thereby oxidizing tryptophan and/or tyrosine to their corresponding pyruvic acid derivative.

Alternatively, it is suggested that NpR1269, a putative prephenate dehydrogenase, generates $p$-hydroxyphenylpyruvic acid, which is a derivative of tyrosine in the early pathway stages. NpR1276 uses two pyruvic acid derivatives from tryptophan and tyrosine for the synthesis of a labile $\beta$ ketoacid product, which is homologous to the thiamin 
diphosphate- (ThDP-) dependent enzyme acetolactate synthase. NpR1274 possibly catalyzes the intermediate cyclization and decarboxylation of the $\beta$-ketoacid product to form the indole-fused cyclopentane moiety of the pigment [111]. Monomer precursors that are formed then undergo dimerization to produce scytonemin. NpR1263, which was found to be similar to a tyrosinase in melanin biosynthesis, participates in these later oxidative dimerization steps, thereby forming scytonemin [112]. Functional roles of other ORFs and their putative intermediate products for the pigment production are still under investigation.

\section{Concerns regarding the Physiological Role of Pigmented Compounds}

A number of bacterial species, including those inhabiting the vast marine environment, produce a wide variety of pigments that are important to cellular physiology and survival. Many of these natural metabolites were found to have antibiotic, anticancer, and immunosuppressive activities. These secondary metabolites, produced by microorganisms mostly via the quorum sensing mechanism, have the ability to inhibit the growth of or even kill bacteria and other microorganisms at very low concentrations. Due to such diverse and promising activities against different kinds of diseases, these compounds can play an important role in both pharmaceutical and agricultural research.

It still remains uncertain why these pigmented secondary metabolites from bacteria have antibiotic and/or cytotoxic activities. Although, their true physiological role is yet to be fully discovered, there are a few reports that provide reasonable explanations by making comparisons with nonpigmented bacteria. In particular, the relationships between pigment production and toxicity have been studied by Holmström et al. [113], who found that $90 \%$ of all dark-pigmented compounds taken from marine living surfaces showed inhibitory activity towards invertebrate larvae. Two fractions isolated after column chromatography, one colorless and the other a yellowish-green color, were identified as phenazine derivatives from unidentified marine Streptomycete sp. by Pusecker et al. [65]. The colorless fraction was biologically inactive, while the pigmented phenazine derivative showed highly active antibiotic properties. Previous studies have also demonstrated that marine bacterial metabolites with antibiotic properties were always pigmented [114]. Screening of 38 antibiotic-producing bacterial strains revealed that all pigmented bacteria belonging to the PseudomonasAlteromonas group displayed antibiotic activity, while nonpigmented bacteria were inactive.

Considering data from all reported literature, a number of reasonable biological functions for pigment production in bacteria have been established. In general, the pigmented marine isolates seem to play two important roles: firstly, they provide an adaption to environmental conditions, and, secondly, they provide defense against predators [115]. For instance, it has been shown that the brown colored melanin pigments produced by a variety of species, as well as a yellowgreen colored scytonemin pigment isolated from cyanobacteria, protect cells from UV irradiation and desiccation
$[69,93]$. Therefore, in order to adapt to the excessive sunlight and survive under harmful UV irradiation, bacteria must produce these indispensable compounds. Griffiths et al. [116] found that carotenoids, which were later suggested to be a substitute for sterols, are an important structural component of microbial membranes [117] and may protect bacterial cells from photooxidation or damage caused by visible light irradiation.

Several bacterial pigments that act as antagonists by exhibiting antibiotic activity against other organisms can be considered as potent weapons for survival and effective chemical defenses against eukaryotic predators. This class of bioactive agents includes almost all pigmented compounds commonly produced by Pseudoalteromonas, Pseudomonas, and Streptomyces species. These compounds inhibit the settlement of marine invertebrate larvae [118], the germination of algal spores [119] and protect the host surface by interfering with bacterial colonization and biofilm formation [74]. They may also inhibit other organisms that compete for space and nutrients.

Such hypotheses are also supported by a number of studies that found that these bacterial compounds were active against other prokaryotes and even eukaryotes [120-128]. In many studies, pigmented bacterial strains demonstrated a strong and broad range of antibiotic activities against other organisms, while nonpigmented strains did not [74, 129]. A clear correlation between pigment production and antibacterial activities of the two Silicibacter sp. strain TM1040 and Phaeobacter strain 27-4 grown under static conditions was further reported by Bruhn et al. [129]. Mutant strains, which lacked pigment production, also lost their biological activities. Holmström et al. have also shown a close relationship between pigmentation and inhibitory activity, whereby 20 out of 22 dark pigmented bacterial strains tested displayed inhibitory activity against the settlement of two invertebrate larvae and algal spores [113].

Amongst other bacterial strains, Pseudoalteromonas has the most diverse antibiotic activities against alga biofouling, and the dark green pigmented $P$. tunicata exhibits the most active and broadest range of inhibitory activity when compared to other strains from this genus [74]. Two nonpigmented $P$. nigrifaciens and $P$. haloplanktis strains were also found not to display any antibiotic activities using various bioassays [74].

Blue-pigmented pyocyanin production in $P$. aeruginosa (Pup14B) was observed by Angell et al. to be induced by Enterobacter species (Pup14A and KM1), and this pyocyanin displayed moderate antibiotic activity against E. coli and yeast [130]. It was experimentally demonstrated that metabolites produced by Pup14A strain are necessary for the production of this pigment in Pup14B strain [130]. Many other reports describe synergism between bacteria and higher organisms; however, this is a rare example between two bacterial species [131]. Such an unusual case contrasts with the hypothesis of the regulated biodiversity of marine bacteria, in which surface-associated microorganisms produce antimicrobial agents [74] to prevent competing microorganisms. The symbiosis of the two bacterial species is not yet 
fully understood, although both species appear to benefit from the pigment production.

One of the promising biological activities of marine bacteria isolates is their cytotoxic effect against cancer cells. Despite many investigations, the exact molecular mechanism of this pigmented compound cytotoxicity remains undetermined and requires further study. For example, violacein is known to cause apoptosis in tumorous cells [41]. However, the pathways leading to cell death have not yet been linked to the possible effects of the pigment, which was also shown to affect signal transduction agents, such as protein kinase and protein phosphatase family enzymes that play crucial role in cell differentiation and proliferation.

In a study by Bromberg et al., violacein showed inhibitory activity against protein phosphatases isolated from human lymphocytes [132]. A similar study was also conducted by Fürstner et al. to assess the inhibitory activity of prodigiosin derivatives [133]. Other targets of these compounds, including ion channels, are further being investigated [134-137].

Unexpected problems have also arisen when investigating marine environments. While the marine environment is a promising source for identifying microorganisms that can produce important biologically active pigments, yields of these compounds remain variable and are sometimes too low to provide enough material for drug development [138] or commercial applications. The main reason for such low yields is that these compounds are secondary metabolites and production depends on the quorum sensing mechanism.

Despite marine bacteria being capable of growing in the extremely low concentrations of nutrients that often exist in seawater, most species still require seawater or its equivalent as a growth medium for artificial culturing. Seawater is therefore used for the growth of marine bacteria, or similar levels of sodium, potassium, and magnesium chloride are supplemented in cultures. Optimal growth and the production of pigments are only sustained for most bacteria when appropriate salt mixtures are used for culturing, as is the case for the prodigiosin-producing marine Pseudomonas magnesiorubra and Vibrio psychroerythrus, among other marine species. These bacteria grew optimally and produced red pigment when cultured in seawater or its equivalent, while pigment production by the terrestrial Serratia marcescens was inhibited in 3\% sea salts [8].

Enhancing low pigment productivity is one of the main issues facing researchers, and some solutions have already been reported. It is well established that antibiotic production by bacteria might be regulated both qualitatively and quantitatively by the nature of the culture medium. In particular, the addition of individual natural compounds to nutrient media or the use of gene expression methods was found to increase the pigment production far beyond expectations. For example, saturated fatty acids, especially peanut broth, was found to be a better choice in increasing prodigiosin production by 40 -fold (approximately $\sim 39 \mathrm{mg} / \mathrm{mL}$ ) in $S$. marcescens [139].

Undecylprodigiosin synthesis by S. marcescens was also markedly enhanced by the addition of vegetable (soybean, olive, and sunflower) oils $(2-6 \%[\mathrm{v} / \mathrm{v}])$ and amino acids to the fermentation broth $[140,141]$. Violacein production by the recombinant Citrobacter freundii strain, the genes of which were reconstructed from Duganella sp. B2, reached up to $1.68 \mathrm{~g} / \mathrm{L}$, making it fourfold higher than the highest production previously reported [142]. It is anticipated that these methods will facilitate the production of sufficient quantities of many bioactive and pharmacologically important compounds obtained from bacteria of marine origin. These compounds, including prodiginine and violacein, are now considered as potential drug candidates for potentially fatal diseases such as cancer and malaria. Although further improvement of culture methods and technologies for pigment production including recombinant technology is necessary, bioactive compounds from marine bacteria may potentially replace the existing drugs that have lower therapeutic actions.

\section{Conclusions}

Recently, a number of review papers have appeared in the literature, and they give an overview of all investigations of the marine environment and its isolates. While previous reviews have covered the biological activities of natural products isolated from marine microorganisms [115, 143] and other living organisms [144, 145], our paper is the first to review the importance of pigmented compounds from marine origin and their potential pharmacological applications.

Most studies investigating marine microorganisms have shown the efficacy and the potential clinical applications of pigmented secondary metabolites in treating several diseases. These studies have also emphasized the effects of microbial metabolites as antibiotic, anticancer, and immunosuppressive compounds. Despite the enormous difficulty in isolating and harvesting marine bacteria, significant progress has been achieved in this field, and investigations of bioactive compounds produced by these species are rapidly increasing. As such, the number of compounds isolated from marine microorganisms is increasing faster when compared with terrestrial species [95].

Overall, this review of pigmented marine bioactive compounds and their pharmacological applications highlights the importance of discovering novel marine bacterial metabolites. Such compounds have a wide variety of biologically active properties and continue to provide promising avenues for both fundamental sciences and applied biomedical research.

\section{References}

[1] A. W. Bruckner, "Life-saving products from coral reefs," Issues in Science and Technology, vol. 18, no. 3, p. 35, 2002.

[2] P. Hugenholtz and N. R. Pace, "Identifying microbial diversity in the natural environment: a molecular phylogenetic approach," Trends in Biotechnology, vol. 14, no. 6, pp. 190197, 1996.

[3] H. Laatsch, "Marine bacterial metabolites," 2005, http:// wwwuser.gwdg.de/ ucoc/laatsch/Reviews__Books__Patents/ R30_Marine_BacterialMetabolites.pdf.

[4] A. M. S. Mayer, K. B. Glaser, C. Cuevas et al., "The odyssey of marine pharmaceuticals: a current pipeline perspective," 
Trends in Pharmacological Sciences, vol. 31, no. 6, pp. 255265, 2010.

[5] W. Fenical, "Chemical studies of marine bacteria: developing a new resource," Chemical Reviews, vol. 93, no. 5, pp. 16731683, 1993.

[6] N. N. Gerber, "Prodigiosin-like pigments from Actinomadura (Nocardia) pelletieri and Actinomadura madurae," Applied Microbiology, vol. 18, no. 1, pp. 1-3, 1969.

[7] H. Rapoport and K. G. Holden, "The synthesis of prodigiosin," Journal of the American Chemical Society, vol. 84, no. 4, pp. 635-642, 1962.

[8] N. N. Gerber, "Prodigiosin-like pigments," CRC Critical Reviews in Microbiology, vol. 3, no. 4, pp. 469-485, 1975.

[9] N. R. Williamson, P. C. Fineran, T. Gristwood, S. R. Chawrai, F. J. Leeper, and G. P. C. Salmond, "Anticancer and immunosuppressive properties of bacterial prodiginines," Future Microbiology, vol. 2, no. 6, pp. 605-618, 2007.

[10] J. W. Bennett and R. Bentley, "Seeing red: the story of prodigiosin," Advances in Applied Microbiology, vol. 47, pp. $1-32,2000$.

[11] B. Montaner and R. Pérez-Tomás, "The prodigiosins: a new family of anticancer drugs," Current Cancer Drug Targets, vol. 3, no. 1, pp. 57-65, 2003.

[12] N. M. Gandhi, J. R. Patell, J. Gandhi, N. J. De Souza, and H. Kohl, "Prodigiosin metabolites of a marine Pseudomonas species," Marine Biology, vol. 34, no. 3, pp. 223-227, 1976.

[13] M. J. Gauthier, "Alteromonas rubra sp. nov., a new marine antibiotic producing bacterium," International Journal of Systematic Bacteriology, vol. 26, no. 4, pp. 459-466, 1976.

[14] N. N. Gerber and M. J. Gauthier, "New prodigiosin-like pigment from Alteromonas rubra," Applied and Environmental Microbiology, vol. 37, no. 6, pp. 1176-1179, 1979.

[15] D. Fehér, R. S. Barlow, P. S. Lorenzo, and T. K. Hemscheidt, "A 2-substituted prodiginine, 2-( $p$-hydroxybenzyl)prodigiosin, from Pseudoalteromonas rubra," Journal of Natural Products, vol. 71, no. 11, pp. 1970-1972, 2008.

[16] Ø. Enger, H. Nygaard, M. Solberg, G. Schei, J. Nielsen, and I. Dundas, "Characterization of Alteromonas denitrificans sp. nov.," International Journal of Systematic Bacteriology, vol. 37, no. 4, pp. 416-421, 1987.

[17] T. Sawabe, H. Makino, M. Tatsumi et al., "Pseudoalteromonas bacteriolytica sp. nov., a marine bacterium that is the causative agent of red spot disease of Laminaria japonica," International Journal of Systematic Bacteriology, vol. 48, no. 3, pp. 769-774, 1998.

[18] C. Yamamoto, H. Takemoto, K. Kuno et al., "Cycloprodigiosin hydrochloride, a new $\mathrm{H}^{+} / \mathrm{Cl}^{-}$symporter, induces apoptosis in human and rat hepatocellular cancer cell lines in vitro and inhibits the growth of hepatocellular carcinoma xenografts in nude mice," Hepatology, vol. 30, no. 4, pp. 894902, 1999.

[19] S. M. Lewis and W. A. Corpe, "Prodigiosin-producing bacteria from marine sources," Applied Microbiology, vol. 12, no. 1, pp. 13-17, 1964.

[20] G. Gauthier, M. Gauthier, and R. Christen, "Phylogenetic analysis of the genera Alteromonas, Shewanella, and Moritella using genes coding for small-subunit rRNA sequences and division of the genus Alteromonas into two genera, Alteromonas (emended) and Pseudoalteromonas gen. nov., and proposal of twelve new species combinations," International Journal of Systematic Bacteriology, vol. 45, no. 4, pp. 755-761, 1995.

[21] K. Kawauchi, K. Shibutani, H. Yagisawa et al., "A possible immunosuppressant, cycloprodigiosin hydrochloride, obtained from Pseudoalteromonas denitrificans," Biochemical and Biophysical Research Communications, vol. 237, no. 3, pp. 543-547, 1997.

[22] H. S. Kim, M. Hayashi, Y. Shibata et al., "Cycloprodigiosin hydrochloride obtained from Pseudoalteromonas denitrificans is a potent antimalarial agent," Biological and Pharmaceutical Bulletin, vol. 22, no. 5, pp. 532-534, 1999.

[23] J. E. Lazaro, J. Nitcheu, R. Z. Predicala et al., "Heptyl prodigiosin, a bacterial metabolite, is antimalarial in vivo and nonmutagenic in vitro," Journal of Natural Toxins, vol. 11, no. 4, pp. 367-377, 2002.

[24] H. K. Lee, J. Chun, E. Y. Moon et al., "Hahella chejuensis gen. nov., sp. nov., an extracellular- polysaccharide-producing marine bacterium," International Journal of Systematic and Evolutionary Microbiology, vol. 51, no. 2, pp. 661-666, 2001.

[25] W. Y. Shieh, Y. W. Chen, S. M. Chaw, and H. H. Chiu, "Vibrio ruber sp. nov., a red, facultatively anaerobic, marine bacterium isolated from sea water," International Journal of Systematic and Evolutionary Microbiology, vol. 53, no. 2, pp. 479-484, 2003.

[26] H. Yi, Y. H. Chang, H. W. Oh, K. S. Bae, and J. Chun, “Zooshikella ganghwensis gen. nov., sp. nov., isolated from tidal flat sediments," International Journal of Systematic and Evolutionary Microbiology, vol. 53, no. 4, pp. 1013-1018, 2003.

[27] D. Kim, J. S. Lee, Y. K. Park et al., "Biosynthesis of antibiotic prodiginines in the marine bacterium Hahella chejuensis KCTC 2396," Journal of Applied Microbiology, vol. 102, no. 4, pp. 937-944, 2007.

[28] T. Nakashima, M. Kurachi, Y. Kato, K. Yamaguchi, and T. Oda, "Characterization of bacterium isolated from the sediment at coastal area of Omura bay in Japan and several biological activities of pigment produced by this isolate," Microbiology and Immunology, vol. 49, no. 5, pp. 407-415, 2005.

[29] D. A. Austin and M. O. Moss, "Numerical taxonomy of redpigmented bacteria isolated from a lowland river, with the description of a new taxon, Rugamonas rubra gen. nov., sp. nov.," Journal of General Microbiology, vol. 132, no. 7, pp. 1899-1909, 1986.

[30] M. O. Moss, "A note on a prodigiosin-producing pseudomonad isolated from a lowland river," Journal of Applied Bacteriology, vol. 55, no. 2, pp. 373-375, 1983.

[31] L. I. Sly and M. H. Hargreaves, "Two unusual budding bacteria isolated from a swimming pool," Journal of Applied Bacteriology, vol. 56, no. 3, pp. 479-486, 1984.

[32] S. Yada, M. Ohba, K. Enomoto et al., "Analysis of bacterial species in the Muroto deep seawater," Deep Ocean Water Resources, vol. 4, no. 2, pp. 47-56, 2003 (Japanese).

[33] A. Oren and F. Rodríguez-Valera, "The contribution of halophilic Bacteria to the red coloration of saltern crystallizer ponds," Federation of European Materials Societies Microbiology Ecology, vol. 36, no. 2-3, pp. 123-130, 2001.

[34] N. Misawa, Y. Satomi, K. Kondo et al., "Structure and functional analysis of a marine bacterial carotenoid biosynthesis gene cluster and astaxanthin biosynthetic pathway proposed at the gene level," Journal of Bacteriology, vol. 177, no. 22, pp. 6575-6584, 1995.

[35] J. H. Lee, Y. S. Kim, T. J. Choi, W. J. Lee, and Y. T. Kim, "Paracoccus haeundaensis sp. nov., a Gram-negative, halophilic, astaxanthin-producing bacterium," International Journal of Systematic and Evolutionary Microbiology, vol. 54, no. 5, pp. 1699-1702, 2004.

[36] D. Rettori and N. Durán, "Production, extraction and purification of violacein: an antibiotic pigment produced by 
Chromobacterium violaceum," World Journal of Microbiology and Biotechnology, vol. 14, no. 5, pp. 685-688, 1998.

[37] N. Durán and C. F. M. Menck, "Chromobacterium violaceum: a review of pharmacological and industiral perspectives," Critical Reviews in Microbiology, vol. 27, no. 3, pp. 201-222, 2001.

[38] C. Sánchez, A. F. Braña, C. Méndez, and J. A. Salas, "Reevaluation of the violacein biosynthetic pathway and its relationship to indolocarbazole biosynthesis," ChemBioChem, vol. 7, no. 8, pp. 1231-1240, 2006.

[39] S. Asamizu, Y. Kato, Y. Igarashi, and H. Onaka, "VioE, a prodeoxyviolacein synthase involved in violacein biosynthesis, is responsible for intramolecular indole rearrangement," Tetrahedron Letters, vol. 48, no. 16, pp. 2923-2926, 2007.

[40] C. J. Balibar and C. T. Walsh, "In vitro biosynthesis of violacein from L-tryptophan by the enzymes VioA-E from Chromobacterium violaceum," Biochemistry, vol. 45, no. 51, pp. 15444-15457, 2006.

[41] N. Durán, G. Z. Justo, C. V. Ferreira, P. S. Melo, L. Cordi, and D. Martins, "Violacein: properties and biological activities," Biotechnology and Applied Biochemistry, vol. 48, no. 3-4, pp. 127-133, 2007.

[42] C. R. Andrighetti-Fröhner, R. V. Antonio, T. B. CreczynskiPasa, C. R. M. Barardi, and C. M. O. Simões, "Cytotoxicity and potential antiviral evaluation of violacein produced by Chromobacterium violaceum," Memórias do Instituto Oswaldo Cruz, vol. 98, no. 6, pp. 843-848, 2003.

[43] C. Matz, P. Deines, J. Boenigk et al., "Impact of violaceinproducing bacteria on survival and feeding of bacterivorous nanoflagellates," Applied and Environmental Microbiology, vol. 70, no. 3, pp. 1593-1599, 2004.

[44] R. M. Brucker, R. N. Harris, C. R. Schwantes et al., "Amphibian Chemical defense: antifungal metabolites of the microsymbiont Janthinobacterium lividum on the salamander Plethodon cinereus," Journal of Chemical Ecology, vol. 34, no. 11, pp. 1422-1429, 2008.

[45] M. H. Becker, R. M. Brucker, C. R. Schwantes, R. N. Harris, and K. P. C. Minbiole, "The bacterially produced metabolite violacein is associated with survival of amphibians infected with a lethal fungus," Applied and Environmental Microbiology, vol. 75, no. 21, pp. 6635-6638, 2009.

[46] R. N. Harris, R. M. Brucker, J. B. Walke et al., "Skin microbes on frogs prevent morbidity and mortality caused by a lethal skin fungus," International Society for Microbial Ecology Journal, vol. 3, no. 7, pp. 818-824, 2009.

[47] R. D. Hamilton and K. E. Austin, "Physiological and cultural characteristics of Chromobacterium marinum sp. n.," Antonie van Leeuwenhoek, vol. 33, no. 3, pp. 257-264, 1967.

[48] M. J. Gauthier, "Morphological, physiological, and biochemical characteristics of some violet-pigmented bacteria isolated from seawater," Canadian Journal of Microbiology, vol. 22, no. 2, pp. 138-149, 1976.

[49] M. J. Gauthier, J. M. Shewan, D. M. Gibson, and J. V. Lee, "Taxonomic position and seasonal variations in marine neritic environment of some gram-negative antibiotic-producing bacteria," Journal of General Microbiology, vol. 87, no. 2, pp. 211-218, 1975.

[50] S. Yada, Y. Wang, Y. Zou et al., "Isolation and characterization of two groups of novel marine bacteria producing violacein," Marine Biotechnology, vol. 10, no. 2, pp. 128-132, 2008.

[51] S. Hakvåg, E. Fjærvik, G. Klinkenberg et al., "Violaceinproducing Collimonas sp. from the sea surface microlayer of costal waters in Trøndelag, Norway," Marine Drugs, vol. 7, no. 4, pp. 576-588, 2009.
[52] S. A. MacCarthy, T. Sakata, D. Kakimoto, and R. M. Johnson, "Production and isolation of purple pigment by Alteromonas luteoviolacea," Bulletin of the Japanese Society of Scientific Fisheries, vol. 51, no. 3, pp. 479-484, 185.

[53] N. J. Novick and M. E. Tyler, "Isolation and characterization of Pseudoalteromonas luteoviolacea strains with sheathed flagella," International Journal of Systematic Bacteriology, vol. 35, no. 1, pp. 111-113, 1985.

[54] J. M. Turner and A. J. Messenger, "Occurrence, biochemistry and physiology of phenazine pigment production," Advances in Microbial Physiology, vol. 27, no. C, pp. 211-275, 1986.

[55] L. S. Pierson and E. A. Pierson, "Metabolism and function of phenazines in bacteria: impact on the behavior of bacteria in the environment and biotechnological process," Applied Microbiology and Biotechnology, vol. 86, no. 6, pp. 1659-1670, 2010.

[56] J. Gibson, A. Sood, and D. A. Hogan, "Pseudomonas aeruginosa-Candida albicans interactions: localization and fungal toxicity of a phenazine derivative," Applied and Environmental Microbiology, vol. 75, no. 2, pp. 504-513, 2009.

[57] J. B. Laursen and J. Nielsen, "Phenazine natural products: biosynthesis, synthetic analogues, and biological activity," Chemical Reviews, vol. 104, no. 3, pp. 1663-1685, 2004.

[58] S. Saha, R. Thavasi, and S. Jayalakshmi, "Phenazine pigments from Pseudomonas aeruginosa and their application as antibacterial agent and food colourants," Research Journal of Microbiology, vol. 3, no. 3, pp. 122-128, 2008.

[59] A. Nansathit, S. Apipattarakul, C. Phaosiri, P. Pongdontri, S. Chanthai, and C. Ruangviriyachai, "Synthesis, isolation of phenazine derivatives and their antimicrobial activities," Walailak Journal of Science and Techology, vol. 6, no. 1, pp. 79-91, 2009.

[60] H. Ran, D. J. Hassett, and G. W. Lau, "Human targets of Pseudomonas aeruginosa pyocyanin," Proceedings of the National Academy of Sciences of the United States of America, vol. 100, no. 2, pp. 14315-14320, 2003.

[61] G. W. Lau, H. Ran, F. Kong, D. J. Hassett, and D. Mavrodi, "Pseudomonas aeruginosa pyocyanin is critical for lung infection in mice," Infection and Immunity, vol. 72, no. 7, pp. 4275-4278, 2004.

[62] M. W. Tan, S. Mahajan-Miklos, and F. M. Ausubel, "Killing of Caenorhabditis elegans by Pseudomonas aeruginosa used to model mammalian bacterial pathogenesis," Proceedings of the National Academy of Sciences of the United States of America, vol. 96, no. 2, pp. 715-720, 1999.

[63] R. P. Maskey, I. Kock, E. Helmke, and H. Laatsch, "Isolation and structure determination of phenazostatin D, a new phenazine from a marine actinomycete isolate Pseudonocardia sp. B6273," Zeitschrift für Naturforschung, vol. 58b, no. 7, pp. 692-694, 2003.

[64] D. Li, F. Wang, X. Xiao, X. Zeng, Q. Q. Gu, and W. Zhu, "A new cytotoxic phenazine derivative from a deep sea bacterium Bacillus sp.", Archives of Pharmacal Research, vol. 30, no. 5, pp. 552-555, 2007.

[65] K. Pusecker, H. Laatsch, E. Helmke, and H. Weyland, "Dihydrophencomycin methyl ester, a new phenazine derivative from a marine streptomycete," Journal of Antibiotics, vol. 50, no. 6, pp. 479-483, 1997.

[66] R. Wilson, T. Pitt, G. Taylor et al., "Pyocyanin and 1-hydroxyphenazine produced by Pseudomonas aeruginosa inhibit the beating of human respiratory cilia in vitro," Journal of Clinical Investigation, vol. 79, no. 1, pp. 221-229, 1987.

[67] M. Akagawa-Matsushita, T. Itoh, Y. Katayama, H. Kuraishi, and K. Yamasato, "Isoprenoid quinone composition of some 
marine Alteromonas, Marinomonas, Deleya, Pseudomonas and Shewanella species," Journal of General Microbiology, vol. 138, no. 11, pp. 2275-2281, 1992.

[68] R. P. Maskey, E. Helmke, and H. Laatsch, "Himalomycin A and B: isolation and structure elucidation of new fridamycin type antibiotics from a marine Streptomyces isolate," Journal of Antibiotics, vol. 56, no. 11, pp. 942-949, 2003.

[69] P. Z. Margalith, Pigment Microbiology, Chapman \& Hall, London, UK, 1992.

[70] J. Koyama, "Anti-infective quinone derivatives of recent patents," Recent Patents on Anti-Infective Drug Discovery, vol. 1, no. 1, pp. 113-125, 2006.

[71] F. Li, R. P. Maskey, S. Qin et al., "Chinikomycin A and B: isolation, structure elucidation and biological activity of novel antibiotics from a marine Streptomyces sp. isolate M045," Journal of Natural Products, vol. 68, no. 3, pp. 349353, 2005.

[72] C. F. Norton and G. E. Jones, "A marine isolate of Pseudomonas nigrifacience. II. Characterization of its blue pigment," Archiv für Mikrobiologie, vol. 64, no. 4, pp. 369-376, 1969.

[73] H. Kobayashi, Y. Nogi, and K. Horikoshi, "New violet 3,3'bipyridyl pigment purified from deep-sea microorganism Shewanella violacea DSS12," Extremophiles, vol. 11, no. 2, pp. 245-250, 2007.

[74] C. Holmström, S. Egan, A. Franks, S. McCloy, and S. Kjelleberg, "Antifouling activities expressed by marine surface associated Pseudoalteromonas species," Federation of European Materials Societies Microbiology Ecology, vol. 41, no. 1, pp. 47-58, 2002.

[75] S. Egan, S. James, C. Holmström, and S. Kjelleberg, "Correlation between pigmentation and antifouling compounds produced by Pseudoalteromonas tunicate," Environmental Microbiology, vol. 4, no. 8, pp. 433-442, 2002.

[76] A. Franks, P. Haywood, C. Holmström, S. Egan, S. Kjelleberg, and N. Kumar, "Isolation and structure elucidation of a novel yellow pigment from the marine bacterium Pseudoalteromonas tunicata," Molecules, vol. 10, no. 10, pp. 1286-1291, 2005.

[77] B. Carté and D. J. Faulkner, "Defensive metabolites from three nembrothid nudibranchs," Journal of Organic Chemistry, vol. 48, no. 14, pp. 2314-2318, 1983.

[78] N. Lindquist and W. Fenical, "New tambjamines class alkaloids from the marine ascidian Atapozoa sp. and its nudibranch predators. Origin of the tambjamines in Atapozoa," Experientia, vol. 47, no. 5, pp. 504-506, 1991.

[79] A. J. Blackman and C. P. Li, "New tambjamine alkaloids from the marine bryozoan Bugula dentate," Australian Journal of Chemistry, vol. 47, no. 8, pp. 1625-1629, 1994.

[80] D. M. Pinkerton, M. G. Banwell, M. J. Garson et al., "Antimicrobial and cytotoxic activities of synthetically derived tambjamines C and E-J, BE-18591, and a related alkaloid from the marine bacterium Pseudoalteromonas tunicata," Chemistry \& Biodiversity, vol. 7, no. 5, pp. 1311-1324, 2010.

[81] A. C. Granato, J. H. H. L. de Oliveira, M. H. R. Seleghim et al., "Produtos naturais da ascidia Botrylloides giganteum, das esponjas Verongula gigantea, Ircinia felix, Cliona delitrix e do nudibrânquio Tambja eliora, da costa do Brasil," Quimica Nova, vol. 28, no. 2, pp. 192-198, 2005.

[82] D. M. Pinkerton, M. G. Banwell, and A. C. Willis, "Total syntheses of tambjamines C, E, F, G, H, I and J, BE-18591, and a related alkaloid from the marine bacterium Pseudoalteromonas tunicata," Organic Letters, vol. 9, no. 24, pp. 51275130, 2007.

[83] S. I. Kotob, S. L. Coon, E. J. Quintero, and R. M. Weiner, "Homogentisic acid is the primary precursor of melanin synthesis in Vibrio cholerae, a Hyphomonas strain, and Shewanella colwelliana," Applied and Environmental Microbiology, vol. 61, no. 4, pp. 1620-1622, 1995.

[84] C. Ruzafa, A. Sanchez-Amat, and F. Solano, "Characterization of the melanogenic system in Vibrio cholerae, ATCC 14035," Pigment Cell Research, vol. 8, no. 3, pp. 147-152, 1995.

[85] E. P. Ivanova, E. A. Kiprianova, V. V. Mikhailov et al., "Characterization and identification of marine Alteromonas nigrifaciens strains and emendation of the description," International Journal of Systematic Bacteriology, vol. 46, no. 1, pp. 223-228, 1996.

[86] W. C. Fuqua and R. M. Weiner, "The melA gene is essential for melanin biosynthesis in the marine bacterium Shewanella colwelliana," Journal of General Microbiology, vol. 139, no. 5, pp. 1105-1114, 1993.

[87] A. Sanchez-Amat, C. Ruzafa, and F. Solano, "Comparative tyrosine degradation in Vibrio cholerae strains. The strain ATCC 14035 as a prokaryotic melanogenic model of homogentisate-releasing cell," Comparative Biochemistry and Physiology-Part B, vol. 119, no. 3, pp. 557-562, 1998.

[88] H. Y. Kahng, B. S. Chung, D. H. Lee, J. S. Jung, J. H. Park, and C. O. Jeon, "Cellulophaga tyrosinoxydans sp. nov., a tyrosinase-producing bacterium isolated from seawater," International Journal of Systematic and Evolutionary Microbiology, vol. 59, no. 4, pp. 654-657, 2009.

[89] W. Fenical and P. R. Jensen, "Marine microorganisms: a new biomedical resource," in Marine Biotechnology, D. H. Attaway and O. R. Zaborsky, Eds., pp. 419-457, Plenum Press, New York, NY, USA, 1993.

[90] H. Claus and H. Decker, "Bacterial tyrosinases," Systematic and Applied Microbiology, vol. 29, no. 1, pp. 3-14, 2006.

[91] F. Solano, E. García, E. P. de Egea, and A. Sanchez-Amat, "Isolation and characterization of strain MMB-1 (CECT 4803), a novel melanogenic marine bacterium," Applied and Environmental Microbiology, vol. 63, no. 9, pp. 3499-3506, 1997.

[92] P. J. Proteau, W. H. Gerwick, F. Garcia-Pichel, and R. Castenholz, "The structure of scytonemin, an ultraviolet sunscreen pigment from the sheaths of cyanobacteria," Experientia, vol. 49, no. 9, pp. 825-829, 1993.

[93] C. S. Stevenson, E. A. Capper, A. K. Roshak et al., "Scytonemin - a marine natural product inhibitor of kinases key in hyperproliferative inflammatory diseases," Inflammation Research, vol. 51, no. 2, pp. 112-114, 2002.

[94] H.-P. Grossart, M. Thorwest, I. Plitzko, T. Brinkhoff, M. Simon, and A. Zeeck, "Production of a blue pigment (glaukothalin) by marine Rheinheimera spp.," International Journal of Microbiology, vol. 2009, Article ID 701735, 7 pages, 2009.

[95] I. Wagner-Döbler, W. Beil, S. Lang, M. Meiners, and H. Laatsch, "Integrated approach to explore the potential of marine microorganisms for the production of bioactive metabolites," Advances in Biochemical Engineering/Biotechnology, vol. 74, pp. 207-238, 2002.

[96] N. R. Williamson, H. T. Simonsen, R. A. A. Ahmed et al., "Biosynthesis of the red antibiotic, prodigiosin, in Serratia: identification of a novel 2-methyl-3-n-amylpyrrole (MAP) assembly pathway, definition of the terminal condensing enzyme, and implications for undecylprodigiosin biosynthesis in Streptomyces," Molecular Microbiology, vol. 56, no. 4, pp. 971-989, 2005.

[97] N. R. Williamson, P. C. Fineran, F. J. Leeper, and G. P. C. Salmond, "The biosynthesis and regulation of bacterial 
prodiginines," Nature Reviews Microbiology, vol. 4, no. 12, pp. 887-899, 2006.

[98] A. K. P. Harris, N. R. Williamson, H. Slater et al., "The Serratia gene cluster encoding biosynthesis of the red antibiotic, prodigiosin, shows species- and strain-dependent genome context variation," Microbiology, vol. 150, no. 11, pp. 35473560, 2004.

[99] H. Jeong, J. H. Yim, C. Lee et al., "Genomic blueprint of Hahella chejuensis, a marine microbe producing an algicidal agent," Nucleic Acids Research, vol. 33, no. 22, pp. 7066-7073, 2005.

[100] A. M. Cerdeño, M. J. Bibb, and G. L. Challis, "Analysis of the prodiginine biosynthesis gene cluster of Streptomyces coelicolor A3(2): new mechanisms for chain initiation and termination in modular multienzymes," Chemistry and Biology, vol. 8, no. 8, pp. 817-829, 2001.

[101] M.-J. Ding and R. P. Williams, "Biosynthesis of prodigiosin by white strains of Serratia marcescens isolated from patients," Journal of Clinical Microbiology, vol. 17, no. 3, pp. 476-480, 1983.

[102] K. Shinoda, T. Hasegawa, H. Sato et al., "Biosynthesis of violacein: a genuine intermediate, protoviolaceinic acid, produced by VioABDE, and insight into VioC function," Chemical Communications, no. 40, pp. 4140-4142, 2007.

[103] S. Hirano, S. Asamizu, H. Onaka, Y. Shiro, and S. Nagano, "Crystal structure of VioE, a key player in the construction of the molecular skeleton of violacein," Journal of Biological Chemistry, vol. 283, no. 10, pp. 6459-6466, 2008.

[104] K. S. Ryan, C. J. Balibar, K. E. Turo, C. T. Walsh, and C. L. Drennan, "The violacein biosynthetic enzyme VioE shares a fold with lipoprotein transporter proteins," Journal of Biological Chemistry, vol. 283, no. 10, pp. 6467-6475, 2008.

[105] G. S. Byng, D. C. Eustice, and R. A. Jensen, "Biosynthesis of phenazine pigments in mutant and wild-type cultures of Pseudomonas aeruginosa," Journal of Bacteriology, vol. 138, no. 3, pp. 846-852, 1979.

[106] D. V. Mavrodi, R. F. Bonsall, S. M. Delaney, M. J. Soule, G. Phillips, and L. S. Thomashow, "Functional analysis of genes for biosynthesis of pyocyanin and phenazine-1-carboxamide from Pseudomonas aeruginosa PAO1," Journal of Bacteriology, vol. 183, no. 21, pp. 6454-6465, 2001.

[107] C. Burke, T. Thomas, S. Egan, and S. Kjelleberg, "The use of functional genomics for the identification of a gene cluster encoding for the biosynthesis of an antifungal tambjamine in the marine bacterium Pseudoalteromonas tunicate," Environmental Microbiology, vol. 9, no. 3, pp. 814-818, 2007.

[108] D. López-Serrano, F. Solano, and A. Sanchez-Amat, "Identification of an operon involved in tyrosinase activity and melanin synthesis in Marinomonas mediterranea," Gene, vol. 342, no. 1, pp. 179-187, 2004.

[109] S. K. Kelley, V. E. Coyne, D. D. Sledjeski, W. C. Fuqua, and R. M. Weiner, "Identification of a tyrosinase from a periphytic marine bacterium," Federation of European Materials Societies Microbiology Letters, vol. 67, no. 3, pp. 275-279, 1990.

[110] T. Soule, V. Stout, W. D. Swingley, J. C. Meeks, and F. Garcia-Pichel, "Molecular genetics and genomic analysis of scytonemin biosynthesis in Nostoc punctiforme ATCC 29133," Journal of Bacteriology, vol. 189, no. 12, pp. 4465-4472, 2007.

[111] E. P. Balskus and C. T. Walsh, "An enzymatic cyclopen$\operatorname{tyl}[b]$ indole formation involved in scytonemin biosynthesis," Journal of the American Chemical Society, vol. 131, no. 41, pp. 14648-14649, 2009.

[112] E. P. Balskus and C. T. Walsh, "Investigating the initial steps in the biosynthesis of cyanobacterial sunscreen scytonemin,"
Journal of the American Chemical Society, vol. 130, no. 46, pp. 15260-15261, 2008.

[113] C. Holmström, S. James, S. Egan, and S. Kjelleberg, "Inhibition of common fouling organisms by pigmented marine bacterial isolates with special reference to the role of pigmented bacteria," Biofouling, vol. 10, no. 1-3, pp. 251-259, 1996.

[114] M. L. Lemos, A. E. Toranzo, and J. L. Barja, "Antibiotic activity of epiphytic bacteria isolated from intertidal seaweeds," Microbial Ecology, vol. 11, no. 2, pp. 149-163, 1985.

[115] I. Bhatnagar and S. K. Kim, "Immense essence of excellence: marine microbial bioactive compounds," Marine Drugs, vol. 8, no. 10, pp. 2673-2701, 2010.

[116] M. Griffiths, W. R. Sistrom, G. Cohen-Bazire, and R. Y. Stanier, "Function of carotenoids in photosynthesis," Nature, vol. 176, no. 4495, pp. 1211-1214, 1955.

[117] S. Rottem and O. Markowitz, "Carotenoids act as reinforcers of the Acholeplasma laidlawii lipid bilayer," Journal of Bacteriology, vol. 140, no. 3, pp. 944-948, 1979.

[118] C. Holmström, D. Rittschof, and S. Kjelleberg, "Inhibition of settlement by larvae of Balanus amphitrite and Ciona intestinalis by a surface-colonizing marine bacterium," Applied and Environmental Microbiology, vol. 58, no. 7, pp. 2111-2115, 1992.

[119] S. Egan, S. James, C. Holmström, and S. Kjelleberg, "Inhibition of algal spore germination by the marine bacterium Pseudoalteromonas tunicata," Federation of European Microbiological Societies Microbiology Ecology, vol. 35, no. 1, pp. 6773, 2001.

[120] S. Egan, T. Thomas, C. Holmström, and S. Kjelleberg, "Phylogenetic relationship and antifouling activity of bacterial epiphytes from the marine alga Ulva lactuca," Environmental Microbiology, vol. 2, no. 3, pp. 343-347, 2000.

[121] R. J. Andersen, M. S. Wolfe, and D. J. Faulkner, "Autotoxic antibiotic production by a marine Chromobacterium," Marine Biology, vol. 27, no. 4, pp. 281-285, 1974.

[122] M. J. Gauthier and G. N. Flatau, "Antibacterial activity of marine violet-pigmented Alteromonas with special reference to the production of brominated compounds," Canadian Journal of Microbiology, vol. 22, no. 11, pp. 1612-1619, 1976.

[123] C. Holmström and S. Kjelleberg, "The effect of external biological factors on settlement of marine invertebrates and new antifouling technology," Biofouling, vol. 8, no. 2, pp. 147-160, 1994.

[124] C. Holmström, P. Steinberg, V. Christov, G. Christie, and S. Kjelleberg, "Bacteria immobilised in gels: improved methodologies for antifouling and biocontrol applications," Biofouling, vol. 15, no. 1-3, pp. 109-117, 2000.

[125] I. Imai, Y. Ishida, K. Sakaguchi, and Y. Hata, "Algicidal marine bacteria isolated from northern Hiroshima Bay, Japan," Fisheries Science, vol. 61, no. 4, pp. 628-636, 1995.

[126] C. Lovejoy, J. P. Bowman, and G. M. Hallegraeff, "Algicidal effects of a novel marine Pseudoalteromonas isolate (class Proteobacteria, gamma subdivision) on harmful algal bloom species of the genera Chattonella, Gymnodinium, and Heterosigma," Applied and Environmental Microbiology, vol. 64, no. 8, pp. 2806-2813, 1998.

[127] J. S. Maki, D. Rittschof, and R. Mitchell, "Inhibition of larval barnacle attachment to bacterial films: an investigation of physical properties," Microbial Ecology, vol. 23, no. 1, pp. 97106, 1992.

[128] S. A. Mary, S. V. Mary, D. Rittschof, and R. Nagabhushanam, "Bacterial-barnacle interaction: potential of using juncellins and antibiotics to alter structure of bacterial communities," 
Journal of Chemical Ecology, vol. 19, no. 10, pp. 2155-2167, 1993.

[129] J. B. Bruhn, L. Gram, and R. Belas, "Production of antibacterial compounds and biofilm formation by Roseobacter species are influenced by culture conditions," Applied and Environmental Microbiology, vol. 73, no. 2, pp. 442-450, 2007.

[130] S. Angell, B. J. Bench, H. Williams, and C. M. H. Watanabe, "Pyocyanin isolated from a marine microbial population: synergistic production between two distinct bacterial species and mode of action," Chemistry \& Biology, vol. 13, no. 12, pp. 1349-1359, 2006.

[131] H. B. Bode, "No need to be pure: mix the cultures!," Chemistry and Biology, vol. 13, no. 12, pp. 1245-1246, 2006.

[132] N. Bromberg, G. Z. Justo, M. Haun, N. Durán, and C. V. Ferreira, "Violacein cytotoxicity on human blood lymphocytes and effect on phosphatases," Journal of Enzyme Inhibition and Medicinal Chemistry, vol. 20, no. 5, pp. 449-454, 2005.

[133] A. Fürstner, K. Reinecke, H. Prinz, and H. Waldmann, "The core structures of roseophilin and the prodigiosin alkaloids define a new class of protein tyrosine phosphatase inhibitors," ChemBioChem, vol. 5, no. 11, pp. 1575-1579, 2004.

[134] T. Sato, H. Konno, Y. Tanaka et al., "Prodigiosins as a new group of $\mathrm{H}^{+} / \mathrm{Cl}^{-}$symporters that uncouple proton translocators," Journal of Biological Chemistry, vol. 273, no. 34, pp. 21455-21462, 1998.

[135] S. Ohkuma, T. Sato, M. Okamoto et al., "Prodigiosins uncouple lysosomal vacuolar-type ATPase through promotion of $\mathrm{H}^{+} / \mathrm{Cl}^{-}$symport," Biochemical Journal, vol. 334, no. 3, pp. 731-741, 1998.

[136] J. L. Seganish and J. T. Davis, "Prodigiosin is a chloride carrier that can function as an anion exchanger," Chemical Communications, no. 46, pp. 5781-5783, 2005.

[137] K. Kawauchi, K. Tobiume, K. Iwashita et al., "Cycloprodigiosin hydrochloride activates the Ras-PI3K-Akt pathway and suppresses protein synthesis inhibition-induced apoptosis in PC12 cells," Bioscience, Biotechnology and Biochemistry, vol. 72, no. 6, pp. 1564-1570, 2008.

[138] D. S. Bhakuni and D. S. Rawat, Bioactive Marine Natural Products, Springer, New York, NY, USA, 2005.

[139] A. V. Giri, N. Anandkumar, G. Muthukumaran, and G. Pennathur, "A novel medium for the enhanced cell growth and production of prodigiosin from Serratia marcescens isolated from soil," BMC Microbiology, vol. 4, no. 11, pp. 1-10, 2004.

[140] Y.-H. Wei and W. C. Chen, "Enhanced production of prodigiosin-like pigment from Serratia marcescens $\mathrm{SM} \Delta \mathrm{R}$ by medium improvement and oil-supplementation strategies," Journal of Bioscience and Bioengineering, vol. 99, no. 6, pp. 616-622, 2005.

[141] Y.-H. Wei, W.-J. Yu, and W.-C. Chen, "Enhanced undecylprodigiosin production from Serratia marcescens SS-1 by medium formulation and amino-acid supplementation," Journal of Bioscience and Bioengineering, vol. 100, no. 4, pp. 466-471, 2005.

[142] P. X. Jiang, H. S. Wang, C. Zhang, K. Lou, and X. H. Xing, "Reconstruction of the violacein biosynthetic pathway from Duganella sp. B2 in different heterologous hosts," Applied Microbiology and Biotechnology, vol. 86, no. 4, pp. 1077-1088, 2010.

[143] A. Debbab, A. H. Aly, W. H. Lin, and P. Proksch, "Bioactive compounds from marine bacteria and fungi," Microbial Biotechnology, vol. 3, no. 5, pp. 544-563, 2010.

[144] J. W. Blunt, B.-R. Copp, W. P. Hu, M. H. G. Munro, P. T. Northcote, and M. R. Prinsep, "Marine natural products," Natural Product Reports, vol. 26, no. 2, pp. 170-244, 2009.
[145] R. K. Jha and X. Zi-Rong, "Biomedical compounds from marine organisms," Marine Drugs, vol. 2, no. 3, pp. 123-146, 2004. 


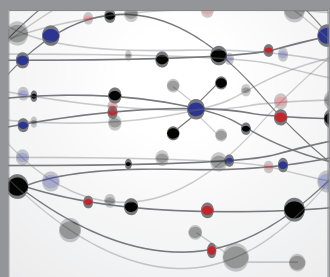

The Scientific World Journal
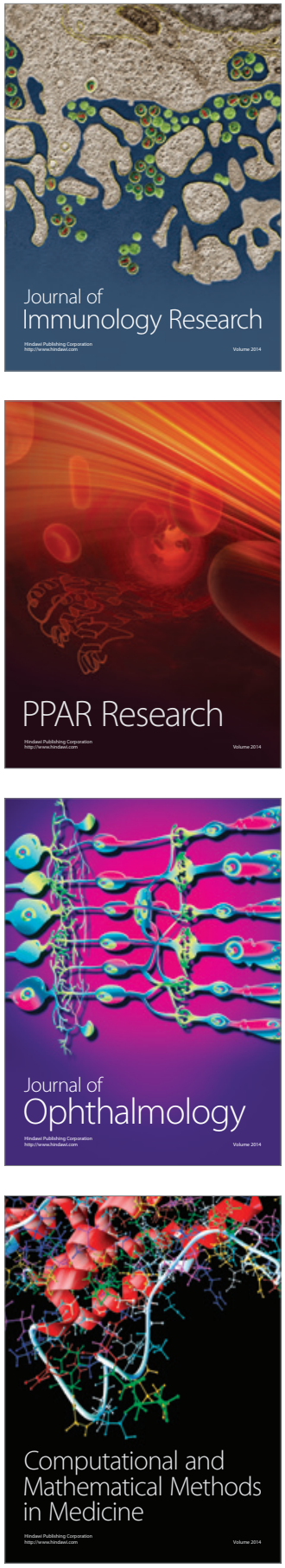

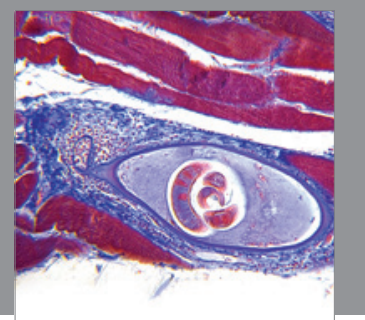

Gastroenterology

Research and Practice
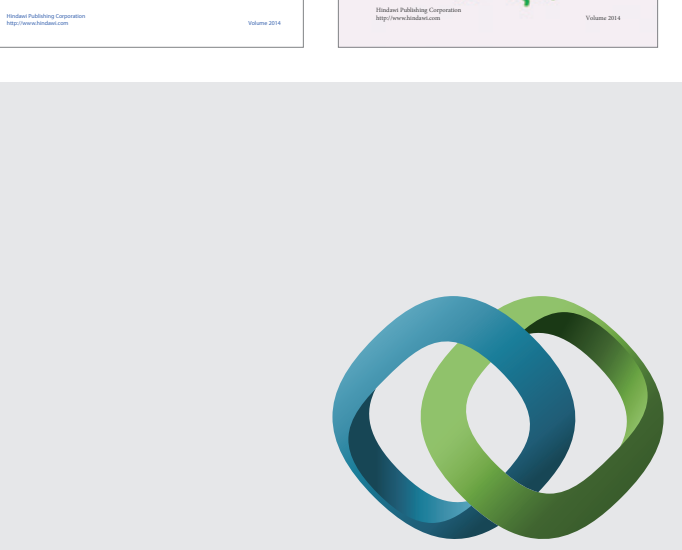

\section{Hindawi}

Submit your manuscripts at

http://www.hindawi.com
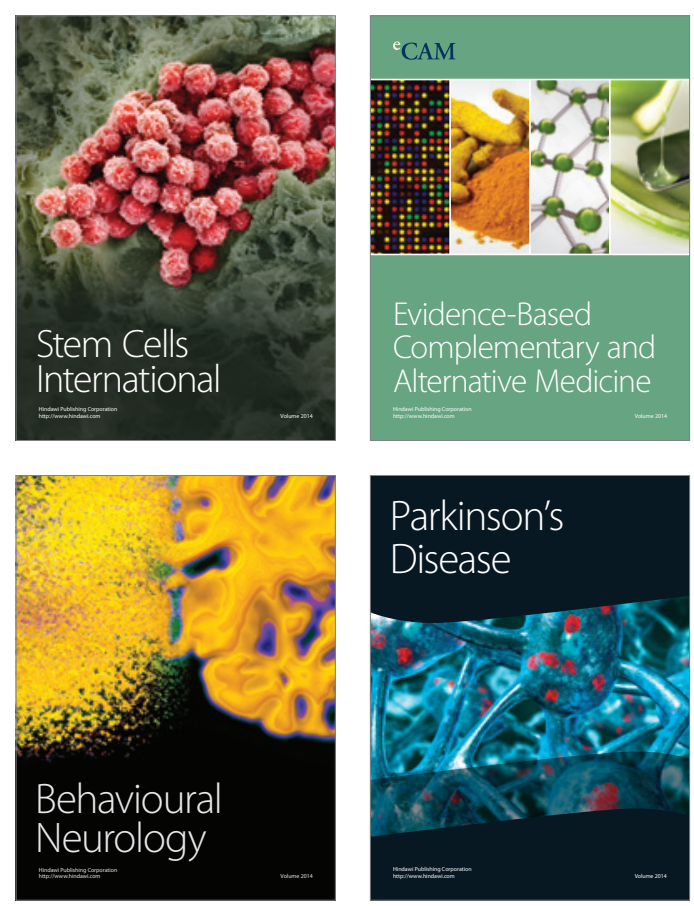

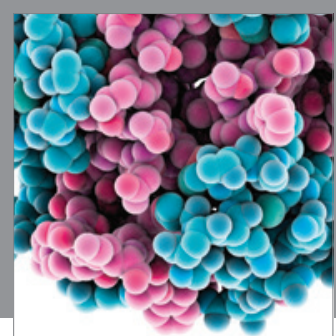

Journal of
Diabetes Research

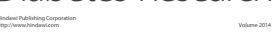

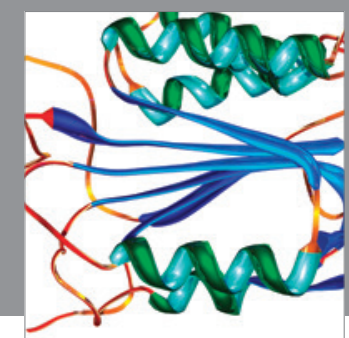

Disease Markers
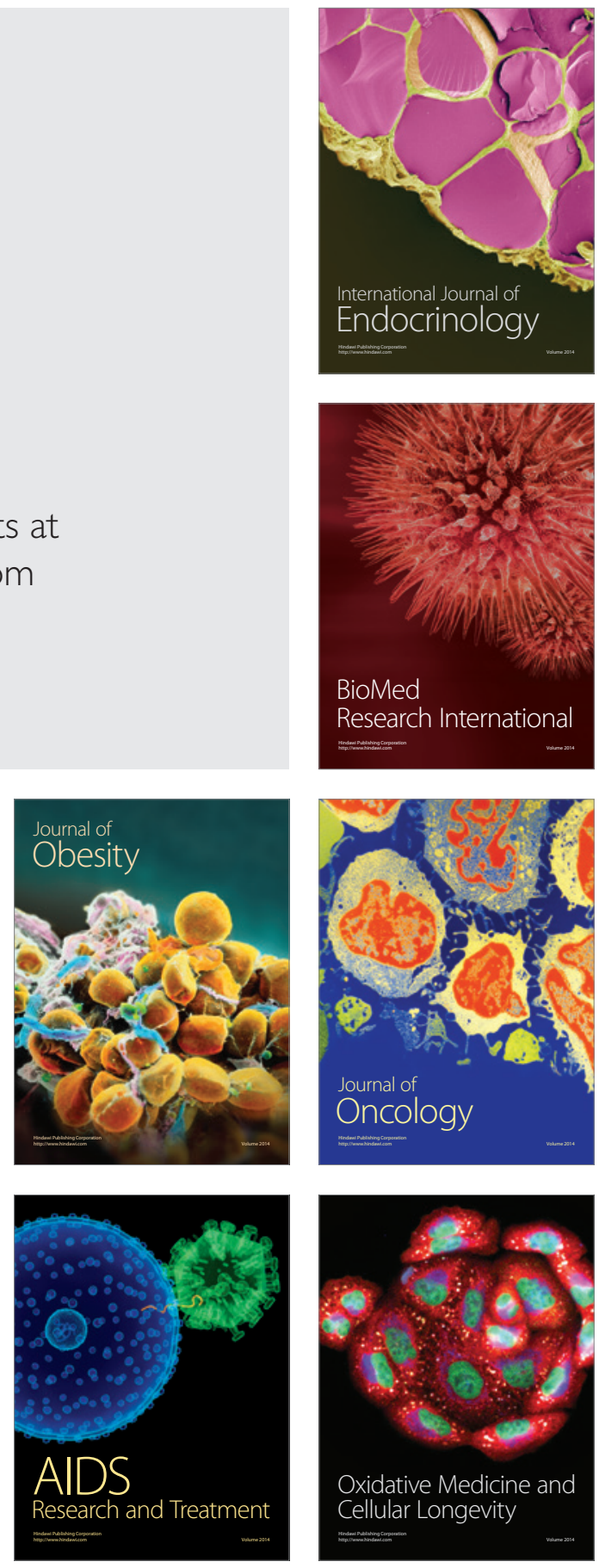